\title{
Revision of the European Rhyacophila fasciata species complex by fine phenomics of the paramere (Trichoptera, Rhyacophilidae)
}

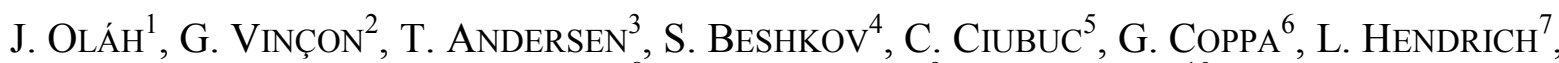 \\ K.A. JOHANSON ${ }^{8}$, J. SALOKANNEL ${ }^{9}$, B. SZCZESNY ${ }^{10}$
}

\author{
${ }^{1} J a ́ n o s$ Oláh, Residence postal address: Tarján u. 28, H-4032 Debrecen, Hungary.E-mail: profolah@gmail.com \\ ${ }^{2}$ Gilles Vinçon, 55 Bd Joseph Vallier,F-38100 Grenoble, France.E-mail: gvincon@gmail.com \\ ${ }^{3}$ Trond Andersen, Department of Natural History, University Museum of Bergen, University of Bergen, P.O. Box \\ 7800, N-5020 Bergen, Norway.E-mail: trond.andersen@um.uib.no \\ ${ }^{4}$ Stoyan Beshkov, National Museum of Natural History, 1 Tsar Osvoboditel Blvd. 1000 Sofia, Bulgaria. \\ E-mail: beshkov@nmnhs.com \\ ${ }^{5}$ Constantin Ciubuc, Sinaia Zoological Research Station, University of Bucharest, Cumpatu 5, Sinaia, R-106100, \\ Romania.E-mail: ciubuc1206@gmail.com \\ ${ }^{6}$ Gennaro Coppa, 1, rue du Courlis, F-08350 Villers-sur-Bar, France.E-mail: gennaro.coppa@wanadoo.fr \\ ${ }^{7}$ Lars Hendrich, Naturwissenschaftliche Sammlungen Bayerns, Zoologisches Staatssammlung, München, \\ Germany.E-mail: hendrich@snsb.de \\ ${ }^{8}$ Kjell Arne Johanson, Swedish Museum of Natural History, Department of Zoology, Box 50007, SE-10405 \\ Stockholm, Sweden.E-mail: kjell.arne.johanson@nrm.se \\ ${ }^{9}$ Juha Salokannel, Siikinkatu 13, 33710 Tampere, Finland.E-mail: juha.salokannel@gmail.com \\ ${ }^{10}$ Bronislaw Szczęsny, Institute of Nature Conservation, Polish Academy of Sciences, Kraków, Poland. 33 A. \\ MickiewiczaAv.31-120 Krakow.E-mail: szczesny@iop.krakow.pl
}

\begin{abstract}
The poorly known, so called widely distributed and highly varying species of the European Rhyacophila fasciata species complex are revised by fine phenomics of the paramere organisation. In this species complex paramere is the most diverse organ. It is the speciation trait integrating the initial split of speciation by its stimulatory and titillating function involved in the early processes of reproductive isolation. Based on paramere organisation and on the character state of distribution three lineages have been delineated in the Rhyacophila fasciata species complex: the European $R$. fasciata lineage, the Caucasian $R$. aliena lineage and the $R$. mysica lineage distributed from Albania to Pakistan. In the $R$. fasciata lineage we have distinguished three clades of species: $R$. fasciata with five species, $R$. matrensis with seven species, and $R$. denticulata with seven species. We have re-diagnosed three known species: $R$. fasciata Hagen, 1859, $R$. denticulata McLachlan, 1879, $R$. sociata Navas, 1916 and described 15 species new to science: $R$. biharensis Oláh sp. nov., $R$. bulgarica Oláh sp. nov., $R$. coppai Oláh sp. nov., $R$. csornahorensis Oláh \& Szczęsny sp. nov., $R$. ferda Oláh sp. nov., $R$. kopasa Oláh \& Coppa sp. nov., $R$. matrensis Oláh, \& Szczęsny sp. nov., R. retezatensis Oláh sp. nov., $R$. rova Oláh \& Coppa sp. nov. $R$. ruda Oláh \& Johanson sp. nov., $R$. salfa Oláh sp. nov., $R$. soreda Coppa \& Oláh sp. nov. $R$. suna Oláh sp. nov., $R$. tuhega Oláh sp. nov., R. zemplenensis Oláh sp. nov. The species status of Rhyacophila gemella Navas, 1923 was reinstated.
\end{abstract}

Keywords. Paramere, fine phenomics, Rhyacophila, species description.

\section{INTRODUCTION}

$\mathrm{D}^{\mathrm{s}}$ ue to epistemological indeterminacies and ambiguities in research amplified by the suppressed state of taxonomy, and the lack of human and financial resources, the taxonomy of many European species remained poorly known mostly stagnating on the nineteenth century results. Such a poorly known caddisfly species is Rhyacophila fasciata Hagen, 1859 described from Elberfeld (Wuppertal), Germany, deposited and curated today in the Harvard University, USA, Massachusetts, Cambridge, and characterized with the status of wide distribution and great 
variability. Moreover, it is one of the most common and abundant stream dwelling animals in the European networks of running waters. This common taxon frequently populates streams of lower elevations and the adults fly almost during the entire season between May and September. Nevertheless, we are unable to determine their phylogenetic species status diverged by the initial split with or without incomplete lineage sorting and secondary admixtures at various levels of standing variation. We work with unknown number of different species having different ecological functions under the name of Rhyacophila fasciata when trying to measure any of their ecosystem services. Malicky and Sipahiler (1993) have tried first to delimit related taxa and established six subspecies inside the Rhyacophila fasciata species complex. Recent studies on the fine phenomics of the adaptive paramere have reinstated the species rank of the taxa reduced previously to subspecies status in the Rhyacophila fasciata species complex (Valladolid et al. 2018, 2019). This paramere focused nomenclatural act was supported by additional male and female morphological characters. Working on the Caucasian relatives we have distinguished three lineages in the R. fasciata species complex (Oláh et al. 2020). Here we revise the mostly European $R$. fasciata lineage of the $R$. fasciata species complex with the description of fifteen new incipient siblings of phylogenetic species.

\section{MATERIAL AND METHODS}

\section{Samples}

This revision of Rhyacophila fasciata, one of the badly known European caddisfly species was realized by putting together samples by many colleagues. They have contributed to this revision and made it possible by their prior scientific activities on the samples. Taxonomy remained without any resources to carry out population sampling of adequate density and frequency indispensable for reliable fine phenomics. Moreover there is lack of taxonomist and there is lack of capability and capacity for fine phenomics. To realize the taxonomic revision of this important component of the European running waters we had to rely on our old cooperation principle of "put together" all the available materials (Oláh et al. 2013). This was really a great "put together" by contributors listed among the authors or in the acknowledgement. This revision is based upon their materials, on their knowledge accumulated in the collected and determined specimens manifesting significant and specialized embodied scientific efforts and results. Due to COVID-19 pandemic the ongoing preparation, administration and posting of type specimens of $R$. denticulata, $R$. fasciata, $R$. septentrionis and of samples from England, Greece, Italy, Romania, and Russia have been suspended. After receiving and examining these types and samples the results will be published in a supplement to this revision.

\section{Species delineation}

Species delineation in the species complex is based primarily on the lateral profile of the parameres with character combination of five male genital structures.

(1) The dorsal shape or dorsal profile of the apicodorsal process on segment IX. Neutral, nonadaptive character with various range of variation.

(2) Lateral shape of the harpago, the second segment of the gonopods. Neutral, non-adaptive character with various range of variation.

(3) The lateral profile of the aedeagus with its mesal and ventral processes. Neutral, non-adaptive character with low diversity within the Rhyacophila fasciata lineage.

(4) The ventral shape of the ventral process on the aedeagus. Neutral, non-adaptive highly varying character. The apparent variation has several sources. The ventral process has a supporting function in copulatory process exposed to functional injuries. Another source of variation is subjective exposed to small variations in the angle of observation.

(5) The lateral profile of the left paramere.

\section{Paramere structure}

In the Rhyacophila fasciata species complex the parameres of the copulatory organ are rather 
produced, large and sophisticated structures performing essential stimulatory titillating or harming functions in the copulatory processes. The paramere consists of (1) the anteriorly expanding basal region; (2) the constricted subbasal region, (3) the highly expanded middle region, that is the basic body of the paramere; (4) the constricted subterminal shaft; (5) the terminal modified seta.

The anteriorly expanded basal region of the paramere forms a conic funnel serving as pivot, fulcrum and giving surface for muscle in the functional motor operation of the paramere.

The variously constricted, abbreviated or elongated subbasal region has constitutive function producing the operational length of the paramere.

The highly expanded middle region is the bulk body of the paramere armed with variously developed band of microtrichia and with variously enlarged spines in various numbers. The shape and extension of microtrichial band has diagnostic value and is rather stable; usually wide anterad and narrowing apicad as running to the dorsum of the subterminal shaft. The variously developed group of large sized spines concentrated usually ventrad at the posterior ending of the middle enlargement.

The constricted subterminal or postspine shaft is variously slender and spine shaped; its elongation has diagnostic value. The microtrichial band stretching from the middle body to its dorsum is delineated ventrad by a well defined ridge running oblique horizontal up to the basement of the terminal seta.

The terminal modified seta is darker pigmented and delineated from the subterminal shaft by remnants of the articulation sulcus. It is variously pointed except Rhyacophila sociata has bifid terminal head formed by the terminal seta and the overrunning of the horizontal ridge on the subterminal paramere shaft.

\section{Depositories.}

Hungarian Natural History Museum, Budapest, Hungary (HNHM)
Museum der Natur, Gotha, Germany (MNG)

National Museum of Natural History, Sofia, Bulgaria (NMNHS)

National Museum, Prague, Czech Republic (NMPC)

Naturalis Biodiversity Center, Zoological Museum, Amsterdam, Netherland (NBC-ZMAN)

Oláh Private Collection, Debrecen, Hungary, under national protection by the Hungarian Natural History Museum, Budapest (OPC).

Swedish Museum of Natural History, Stockholm, Sweden (SMNH)

Zoological Institute, Leningrad, Russia (ZIL)

Zoologische Staatssammlung, München, Germany (ZSM)

\section{TAXONOMY}

\section{Lineage sorting}

(Maps 1-5)

The Rhyacophila fasciata species complex belongs to Rhyacophila vulgaris species group in the Rhyacophila vulgaris branch (Schmid 1970). Based on paramere organization we have delineated three lineages in the complex:

(1) Rhyacophila aliena lineage has broad middle region on the parameres without large spines and with lateral location of microtrichial band. It is distributed form Turkey to Northern Iran (Map $1)$. This lineage is comprised of four species: $R$. aliena Martynov, 1916; R. sp. 1, R. sp. 2 (under description in Oláh et al. 2020); R. talyshica Martynov, 1938.

(2) Rhyacophila mysica lineage has slender parameres without large spines and with mesal location of longitudinal band of microtrichia; distributed from Albania to Pakistan (Map 2). This lineage is comprised of seven species: $R$. ilgazica Sipahiler, 2018; $R$. isparta Sipahiler, 1996; R. ivrizica Sipahiler, 2006; $R$. libanica Malicky \& Sipahiler, 1993; R. mysica Malicky \& Sipahiler, 1993; $R$. sp. 3. Here we describe $R$. tuhega Oláh sp. nov.

(3) The European Rhyacophila fasciata lineage has large spines additional to the microtrichial band located laterad on the parameres. This line- 


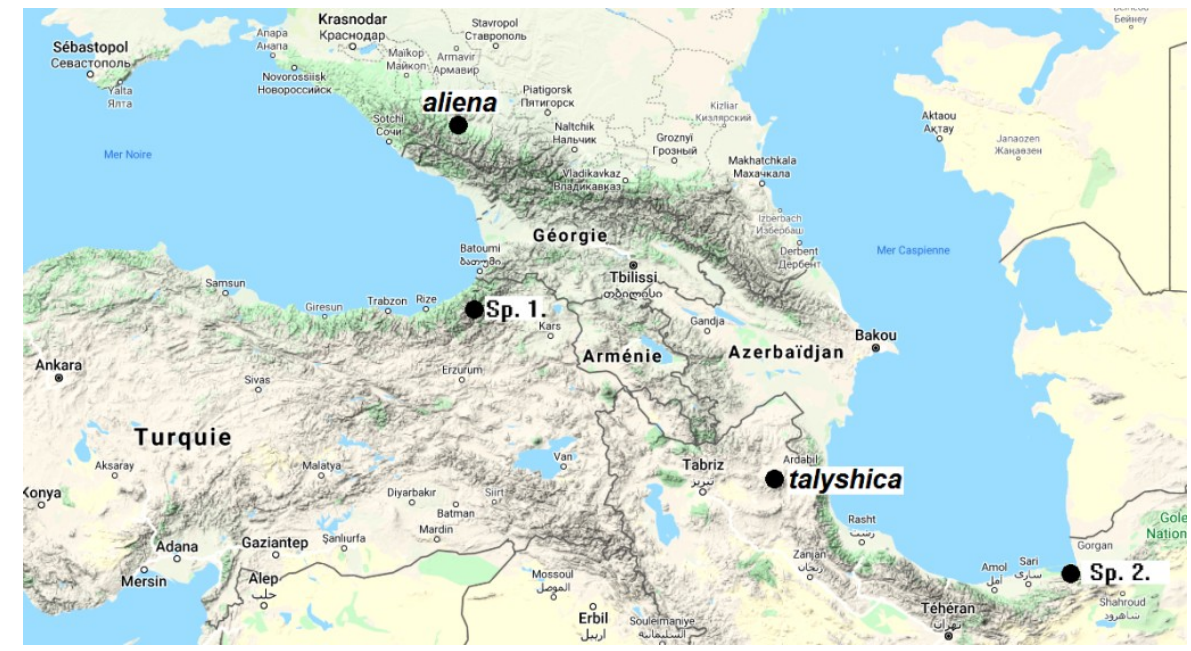

Map 1. Distribution of the Rhyacophila aliena lineage.

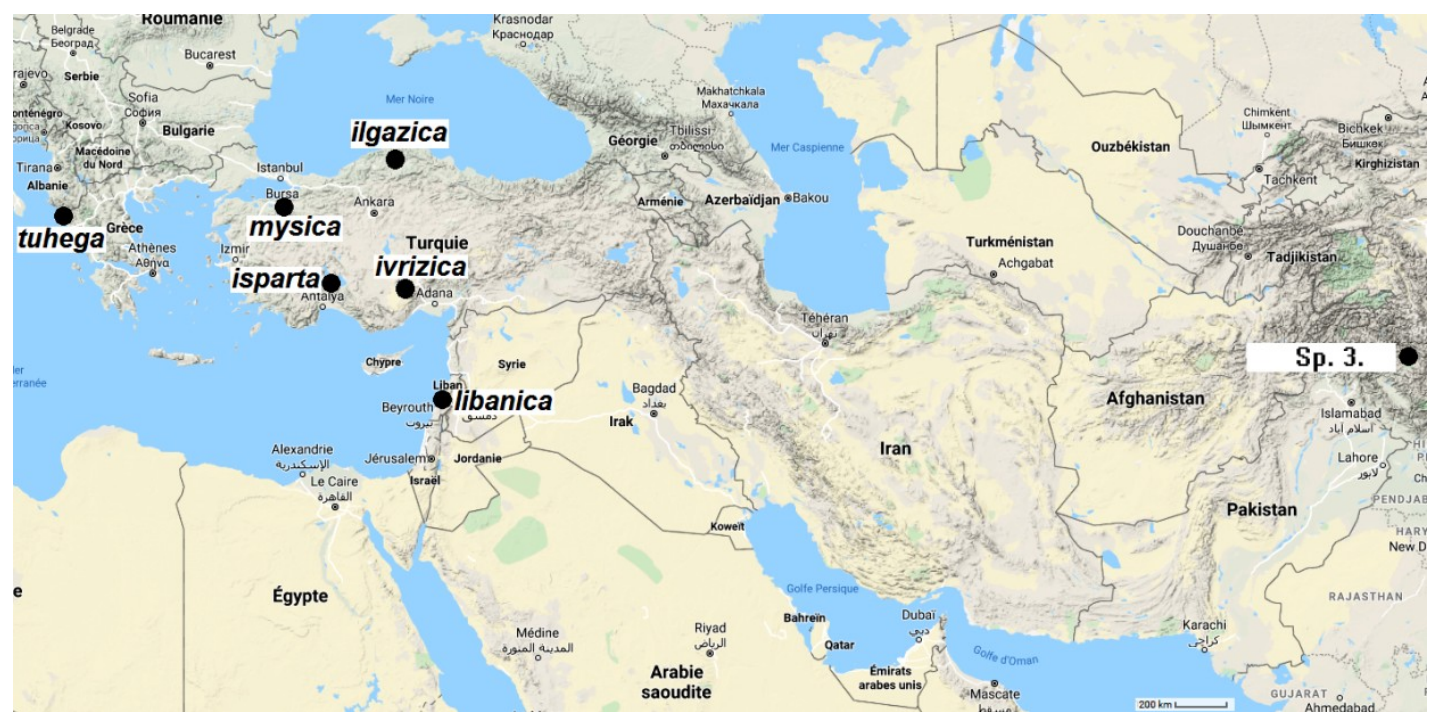

Map 2. Distribution of the Rhyacophila mysica lineage.

age is distributed from northern Spain to North of Finland, Russia and down to Turkey.

Here we have revised the $R$. fasciata lineage and based on paramere organization we have distinguished three clades in the $R$. fasciata lineage:

(a) Rhyacophila fasciata clade characterized by short subterminal paramere shaft compared to the $R$. matrensis clade. This clade is comprised of five species: $R$. fasciata Hagen, 1859, R. ferda $\mathrm{sp}$. nov., $R$. ruda sp. nov., $R$. salfa sp. nov., $R$. suna sp. nov. (Map 3). (b) Rhyacophila matrensis clade characterized by long subterminal paramere shaft compared to the $R$. fasciata clade. This clade is comprised of seven species: $R$. biharensis sp. nov., $R$. bulgarica sp. nov., $R$. csornahorensis sp. nov., $R$. kykladica Malicky \& Sipahiler, 1993, R. matrensis sp. nov., $R$. retezatensis $\mathrm{sp}$. nov., $R$. zemplenensis $\mathrm{sp}$. nov. (Map 4).

(c) Rhyacophila denticulata clade characterized by the highly expanded, broad middle region of the paramere with higher number of large spines ventroapicad. This clade is comprised of altogether seven species in two nested clades (Map 5) 


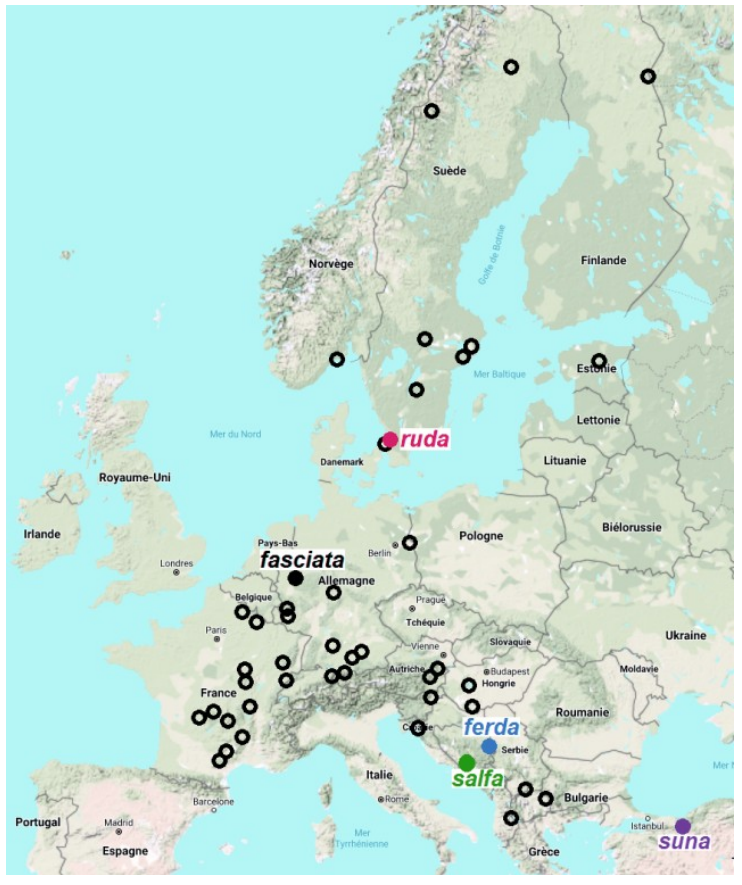

Map 3. Distribution of the Rhyacophila fasciata clade in the Rhyacophila fasciata lineage (full circles represent the type localities).
Rhyacophila denticulata nested clade: This small lineage, having large spines additional to the microtrichia with lateral location on the parameres, belongs to Rhyacophila fasciata lineage of the Rhyacophila fasciata species complex. It is distinguished by the following combination of character states: (1) the ventral extension of the aedeagus has a simple almost vertical lateral profile; (2) several large spines on the paramere ventrum; (3) lateral profile of the paramere is rather flat middle dorsum, without high hump. This lineage is comprised of three species: $R$. denticulata McLachlan 1879, $R$. rova sp. nov., $R$. kopasa sp. nov.

Rhyacophila sociata nested clade: This small lineage, having large spines additional to the microtrichia with lateral location on the parameres, belongs to Rhyacophila fasciata lineage of the Rhyacophila fasciata species complex. It is distinguished by the following combination of character states: (1) the ventral extension of the aedeagus has a triangular lateral profile; (2) several large spines on the paramere ventrum;

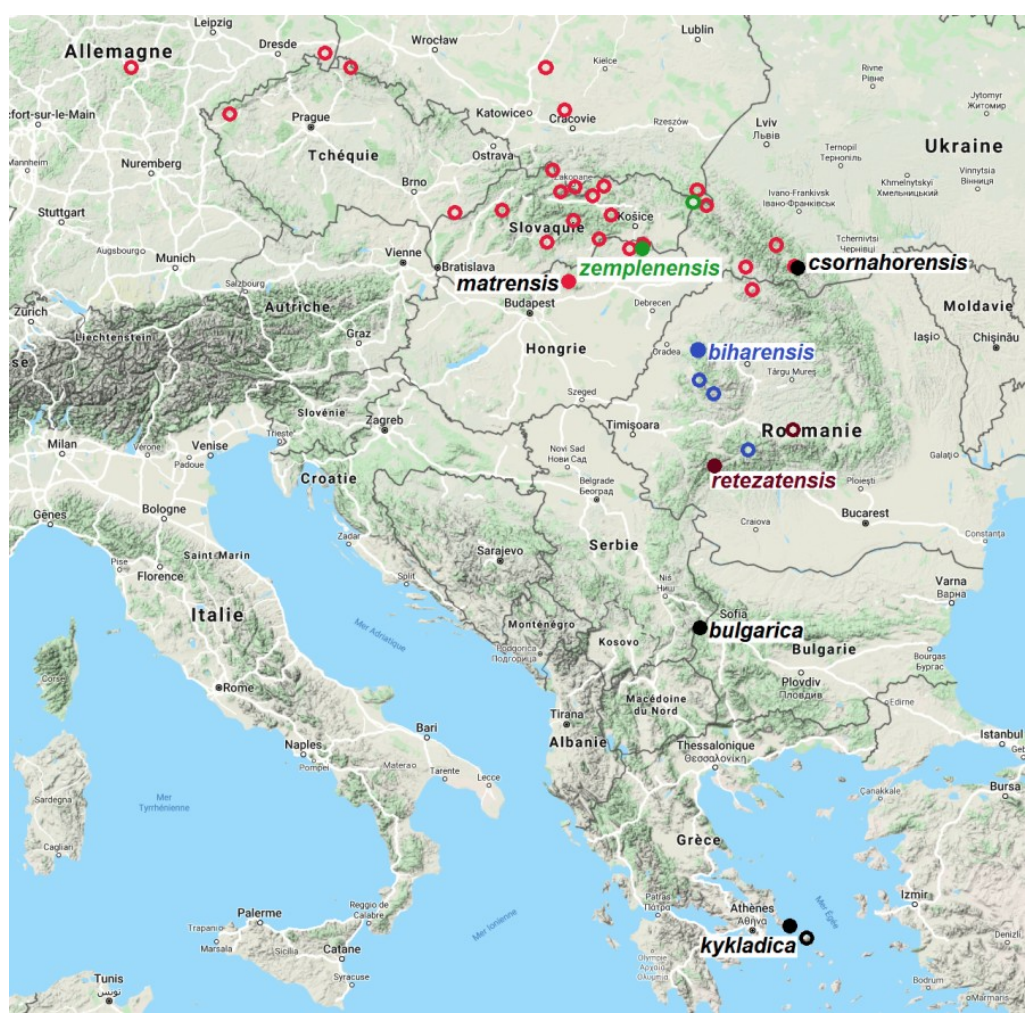

Map 4. Distribution of the Rhyacophila matrensis clade in the Rhyacophila fasciata lineage (full circles represent the type localities). 


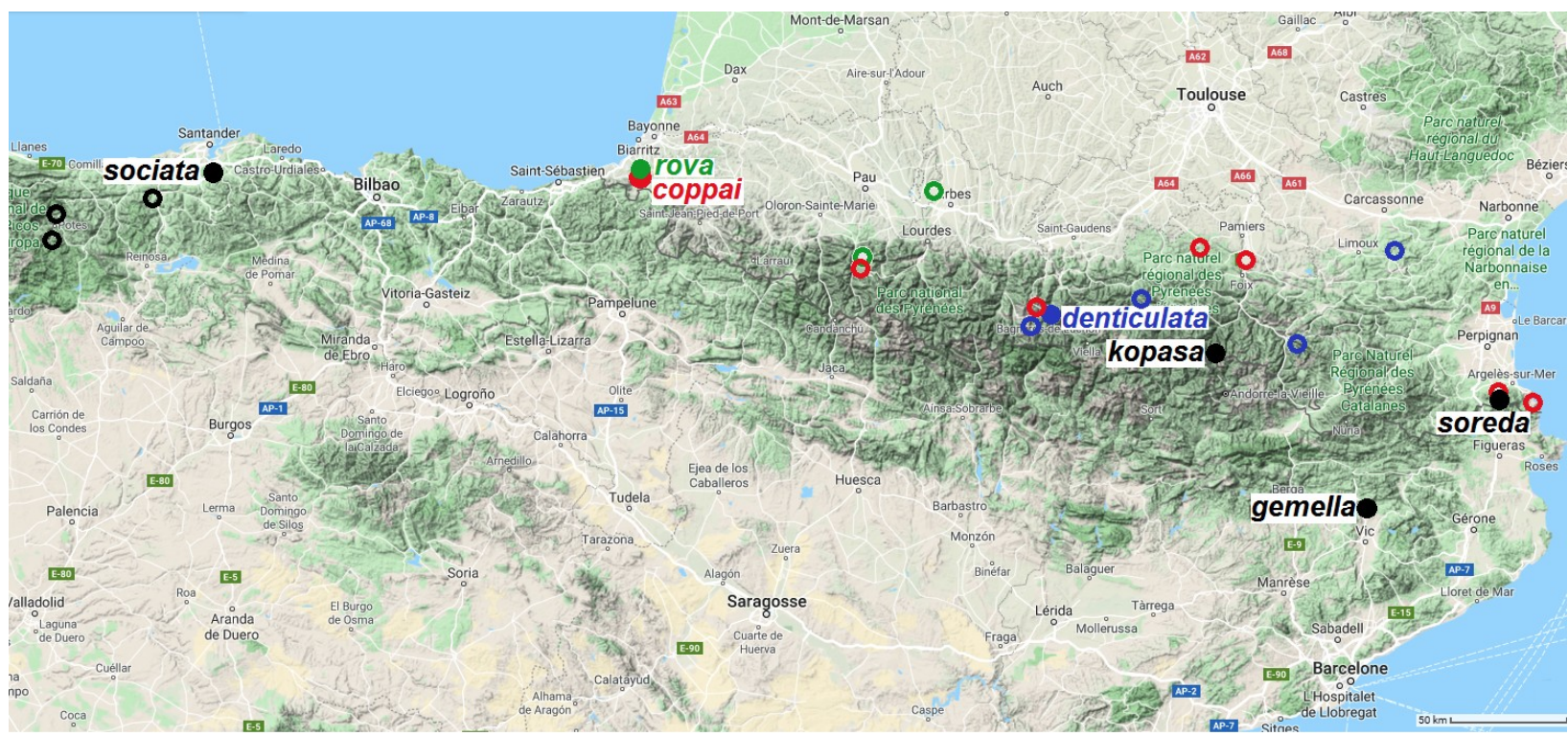

Map 5. Distribution of the Rhyacphila denticulata clade in the Rhyacophila fasciata lineage (full circles represent the type localities).

(3) lateral profile of the paramere with a high hump on middle dorsum. This lineage is comprised of four species: $R$. coppai sp. nov., $R$. gemella Navas, 1923, R. sociata Navas, 1919, $R$. soreda sp. nov. The species status of $R$. gemella need to be reconfirmed by newly collected specimens owing to the loss of the single type.

\section{Rhyacophila biharensis Oláh, sp. nov.}

(Figures 1-9)

Material examined. Holotype: Romania, Apuseni Mts, Sebes Körös valley, Suncuius, near Izbandis spring, 26. X. 2009, leg J. Oláh \& M. Bálint, (1 male, OPC). Paratypes: same as holotype (37 males, 3 females; OPC). Romania, Apuseni Mts. Garda de Sus, tributary of Ariesul Mare, N46 ${ }^{\circ} 270.493$ ' E22 47.895 ', 788m, 29.V. 2013, singled leg. J. Oláh, E. Bajka, Cs. Balogh, \& G. Borics (1 male, OPC). Apuseni Mts. Garda de Sus, tributary of Ariesul Mare, N46 $270.493^{\prime}$ E22 ${ }^{\circ} 47.895$ ', 788m, 19.VI.2013, singled leg. J. Oláh, Cs. Balogh, \& S. Fekete (1 male, OPC). Apuseni Mts., Bihor Mts., Crisul Pietros Saritoarea-Cascade Bohodeiului, N4639' 31,97' E22 ${ }^{\circ}$ 38' 26,25", 1123m, 4.VII.2013, leg. Cs. Balogh,
(1 male, 1 female; OPC). Apuseni Mts. Garda de Sus, tributary of Ariesul Mare, N46 27 ' 30,23” E: $22^{\circ} 47^{\prime} 55,15^{\prime}, 788 \mathrm{~m}, 22$.VIII. 2013, singled leg. Cs. Balogh (2 males, OPC). Romania Sibiului Mts, (Cindrel), Riu Sadu, 770 m, 45.624 24.033, 3.VI.2007, leg. M. Bálint (1 male, OPC).

Description and diagnosis. Head, antennae, maxillary palps, legs and segmental sclerites medium brown. Forewing brown mottled with pale spotted reticulation, very faded in alcohol, forewing length $14 \mathrm{~mm}$. Dorsal shape of the apicodorsal process of segment IX almost circular or slightly ovoid with truncate apex. Lateral shape of the harpago, the second segment of the gonopods obliquely truncate with longer ventrum. The lateral profile of the aedeagus horizontal rather slim. The ventral shape of the ventral process on the aedeagus elongated with rounded head. The lateral profile of the left paramere with elongated middle broadening dilatation; the longitudinal band of the short microtrichia located laterad.

Having large spines and with lateral location of longitudinal band of microtrichia $R$. biharensis sp. nov. belongs to the Rhyacophila fasciata 


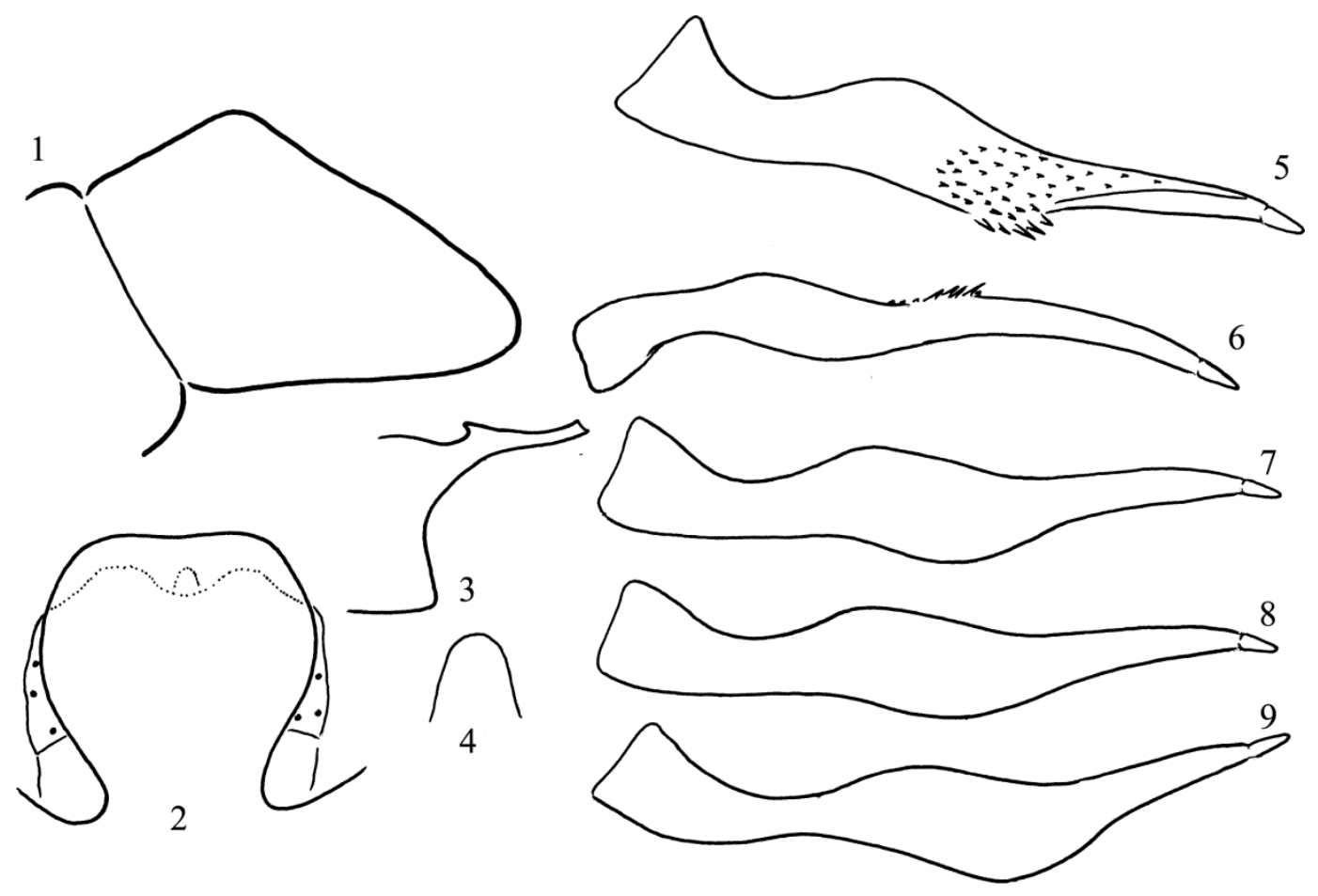

Figures 1-9. Rhyacophila biharensis Oláh, sp. nov. Holotype male: $1=$ left harpago in left lateral view, $2=$ dorsal process on tergite IX in dorsal view, 3 = aedeagus in lateral view, $4=$ ventral process of the aedeagus in ventral view, $5=$ left paramere in lateral view, $6=$ left paramere in ventral view. Paratypes: 7-9 = lateral profile of left paramere.

lineage, as well as having long subterminal paramere shaft it is a member of $R$. matrensis clade of species, most close to $R$. retezatensis sp. nov., but differs by having lateral profile of the left paramere with less elongated broad middle region.

Etymology. Named after the mountainous region of the type locality.

\section{Rhyacophila bulgarica Oláh, sp. nov.}

(Figures 10-18)

Material examined. Holotype: Bulgaria, West Bulgaria, Zelenigread Village, Trun district, 30. IX.1967, leg. A. Popov (1 male, NMNHS).

Description and diagnosis. Head, antennae, maxillary palps, legs and segmental sclerites dark brown. Forewing brown mottled with pale spotted reticulation, very faded in alcohol, forewing length $13 \mathrm{~mm}$. Dorsal shape of the apicodorsal process of segment IX almost regular circular. Lateral shape of the harpago, the second segment of the gonopods obliquely truncate with longer ventrum. The lateral profile of the aedeagus horizontal rather slim. The ventral shape of the ventral process on the aedeagus abbreviated with narrowing head. The lateral profile of the left paramere with extremely elongated middle broadening dilatation; the longitudinal band of the short microtrichia located laterad.

Having large spines and with lateral location of longitudinal band of microtrichia $R$. bulgarica sp. nov. belongs to the Rhyacophila fasciata lineage, as well as having long subterminal paramere shaft it is a member of $R$. matrensis clade of species, most close to $R$. fasciata, but differs by having lateral profile of the left paramere with 

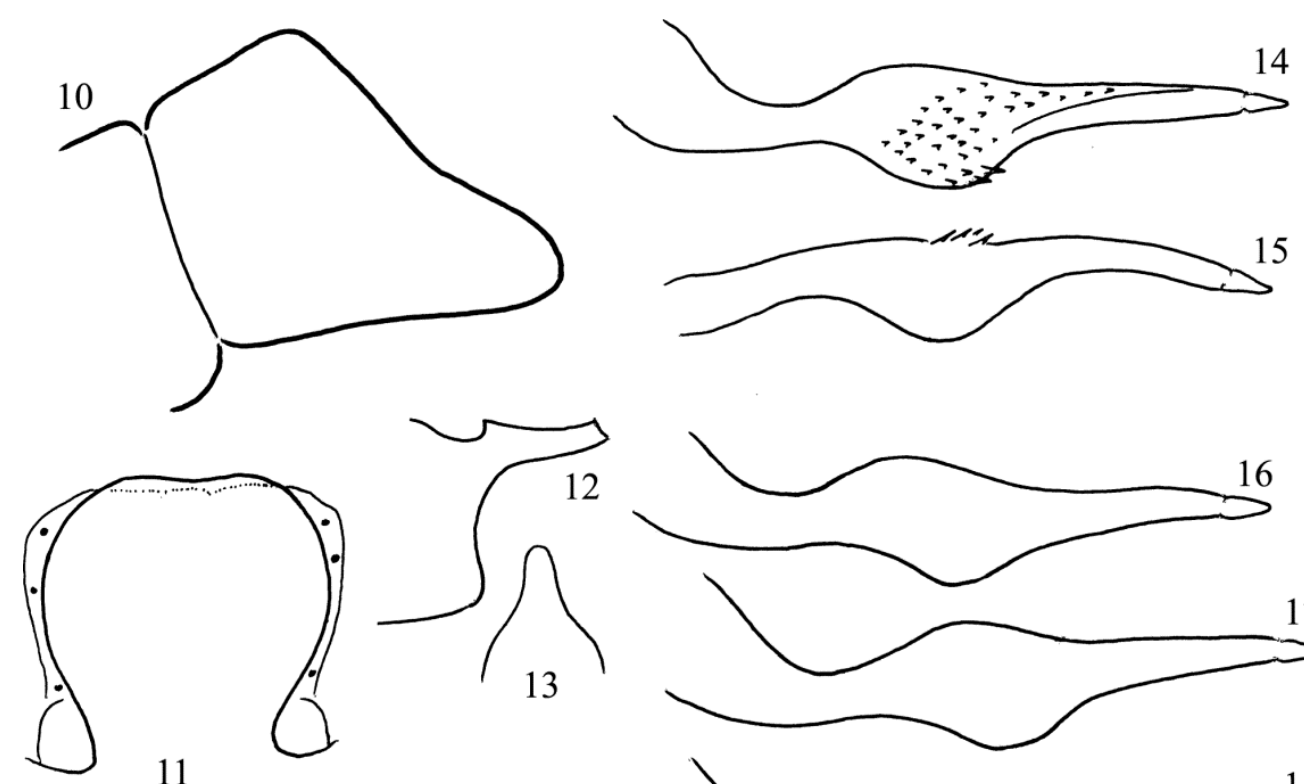

11

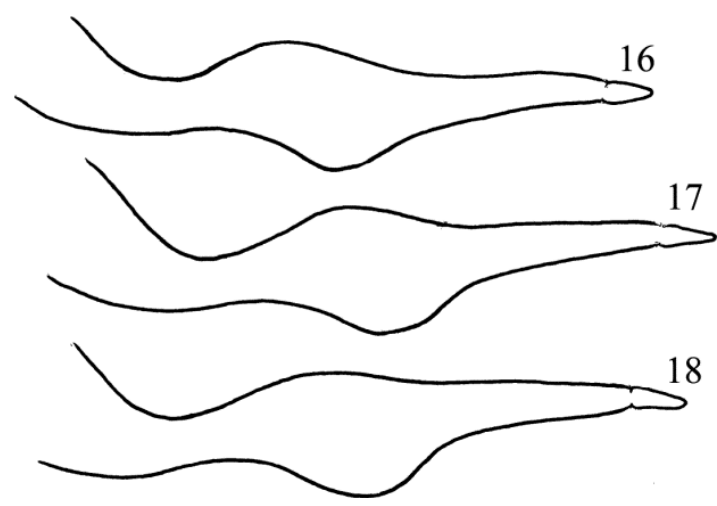

Figures 10-18. Rhyacophila bulgarica Oláh, sp. nov. Holotype male: $10=$ left harpago in left lateral view, $11=$ dorsal process on tergite IX in dorsal view, 12 = aedeagus in lateral view, $13=$ ventral process of the aedeagus in ventral view, 14=left paramere in lateral view, 15 = left paramere in ventral view, $16-18=$ lateral profile of left paramere redrawn or drawn with slight viewing angle modification.

short and extremely broadened middle region. There are well-defined differences in the ventral shape of the ventral process of the aedaegus, but its variability is not known. Moreover the single holotype of $R$. bulgarica has a dark brown sclerite colour compared to the light or median brown colour of R. fasciata.

Etymology. Named after the country of the type locality.

\section{Rhyacophila coppai Oláh, sp. nov.}

(Figures 19-27, 28-29)

Material examined. Holotype: France, Department Pyrénées-Atlantiques, stream along the drainage of Nivelle River, above Saint-Pée-surNivelle, 12-18.VII.1986, light and hand net leg. J. Oláh \& J. Oláh jun. (1 male, OPC). Paratypes: same as holotype (4 males, OPC). France, Department Ariège, Vernajoul, ru de Vernajoul, 370 m,
22.X.2016, leg. G. Coppa (1 male, OPC). France, Department Pyrénées-Atlantiques, Eaux Bonnes, le Valentin amont cascade, 890 m, 10.VII.2010, leg. G. Coppa (1 female, OPC). France, Department Pyrénées-Orientales, Banyuls, ru des Vignes amont Ballaury, 90 m, 29.V.2009, leg. G. Coppa (1 male, 2 females; OPC). France, Department Pyrénées-Orientales, Sorède, rivière de Sorède, en amont de la Vallée Heureuse, 195 m, 26.V.2009, leg. G. Coppa (2 males, 2 females; OPC). France, Department Pyrénées-Orientales, Sorède, la Massane, 195 m, 28.V.2009, leg. G. Coppa (3 males, 2 females; OPC). France, Department HauteGaronne, Cazeaux de Larboust, le Porlet pont D976, 1070m, 12.VII. 2012, leg. G. Coppa (1 male, OPC). France, Department Ariège, Le Maz d'Azil, ru de Camarade, Lamothe, 346m, 20.II. 2008, leg. G. Coppa (1 male, OPC).

Description and diagnosis. Head, antennae, maxillary palps, legs and segmental sclerites dark brown. Forewing brown mottled with pale spotted 


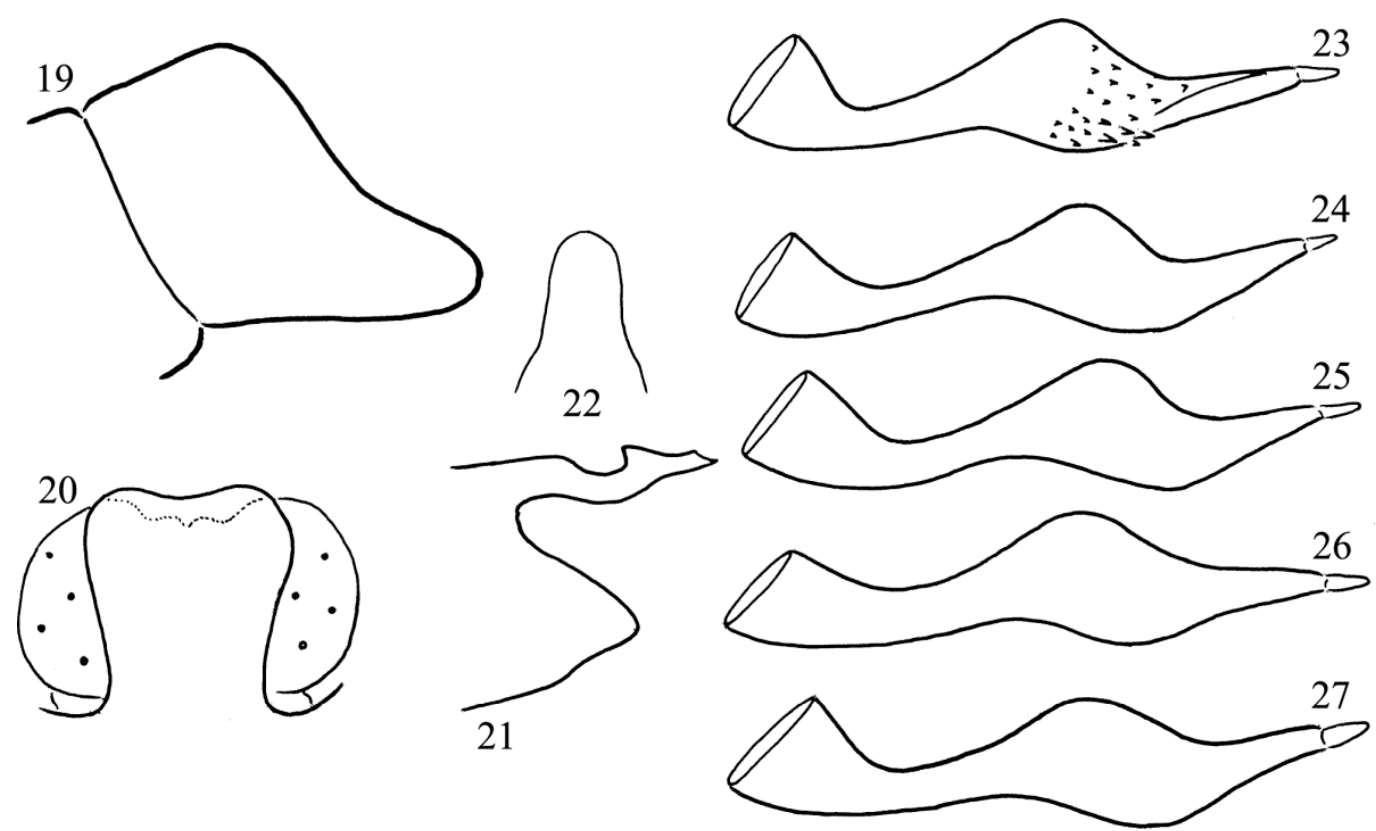

Figures 19-27. Rhyacophila coppai Oláh, sp. nov. Holotype: $19=$ left harpago in left lateral view, $20=$ dorsal process on tergite IX in dorsal view, $21=$ aedeagus in lateral view, $22=$ ventral process of the aedeagus in ventral view, $23=$ left paramere in lateral view. Paratypes: $24-27$ = lateral profile of left paramere.

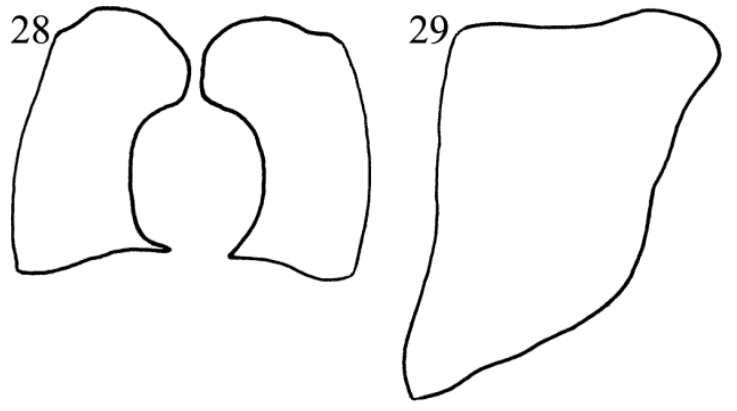

Figures 28-29. Rhyacophila coppai Oláh, sp. nov. Allotype female: 28 = sclerites of segment VIII in dorsal view, $29=$ sclerites of segment VIII in lateral view.

reticulation, very faded in alcohol, forewing length $12 \mathrm{~mm}$. Dorsal shape of the apicodorsal process of segment IX elongated subquadrangular with constricted basal neck. Lateral shape of the harpago, the second segment of the gonopods obliquely truncate with longer ventrum. The lateral profile of the aedeagus horizontal, rather slim and short. The triangular ventral extension of the aedeagus is pointed. The ventral shape of the ventral process on the aedeagus robust digitate slightly broadening basad. The lateral profile of the left paramere with high and short dorsal hump on the middle extension; the longitudinal band of the short microtrichia located laterad and less distributed anterad.

Having large spines and with lateral location of longitudinal band of microtrichia $R$. coppai $\mathrm{sp}$. nov. belongs to the Rhyacophila fasciata lineage. It is a member of $R$. sociata clade nested in $R$. denticulata clade distinguishable by the following combination of character states: the ventral extension of the aedeagus has a triangular lateral profile; lateral profile of the paramere with a high hump on middle dorsum. $R$. coppai sp. nov. is distinguished from $R$. sociata Navas by the very high and short dorsal hump on the middle extension and by the simple, not bifid paramere apex. Moreover, among the neutral, non-adaptive characters the dorsal process of segment IX is less elongated, the harpago with slightly concave apex and the head of the ventral lobe on aedeagus rounded, not excised. The female sclerite complex on segment VIII differs from that of $R$. soreda $\mathrm{sp}$. nov. In dorsal view the apicomesal lobe is narrowing, not broad rounded. We have no female of $R$. sociata to compare. 
Etymology. This probable ancestral species of the Rhyacophila sociata lineage, widely distributed in the Pyrenees, is dedicated to our colleague Gennaro Coppa to remember his highly appreciated scientific activity in caddisfly research.

\section{Rhyacophila csornahorensis Oláh \& Szczęsny, sp. nov.}

(Figures 30-37)

Material examined. Holotype: Ukraine, East Carpathians, Chornohora Mts., Breskulec brook, 1000-1400m, 8.X.2005, leg. B. Szczęsny (1 male, OPC).

Description and diagnosis. Head, antennae, maxillary palps, legs and segmental sclerites medium brown. Forewing brown mottled with pale spotted reticulation, very faded in alcohol, forewing length $14 \mathrm{~mm}$. Dorsal shape of the apicodorsal process of segment IX almost circular with slightly excised apex and rather stout neck. Lateral shape of the harpago, the second segment of the gonopods obliquely truncate with longer ventrum. The lateral profile of the aedeagus hori zontal, rather slim. The ventral shape of the ventral process on the aedeagus elongated with broader base and rounded head. The lateral profile of the left paramere almost regular digitate without middle broadening dilatation; the longitudinal band of the short microtrichia located laterad and accompanied with a single large spine only.

Having large spines and with lateral location of longitudinal band of microtrichia $R$. csornahorensis sp. nov. belongs to the Rhyacophila fasciata lineage, as well as having long subterminal paramere shaft $R$. csornahorensis sp. nov. is a member of $R$. matrensis clade of species and most close to $R$. matrensis sp. nov., but differs by having lateral profile of the left paramere with digitate form and armed with a single large spine only. The dorsal and ventral evenness or smoothness is its most diverged character state. The dorsal process of segment IX seems to differ, but its variability is not known.

Etymology. Named after the mountainous region of the type locality (Chornohora $=$ Csornahora in Hungarian).
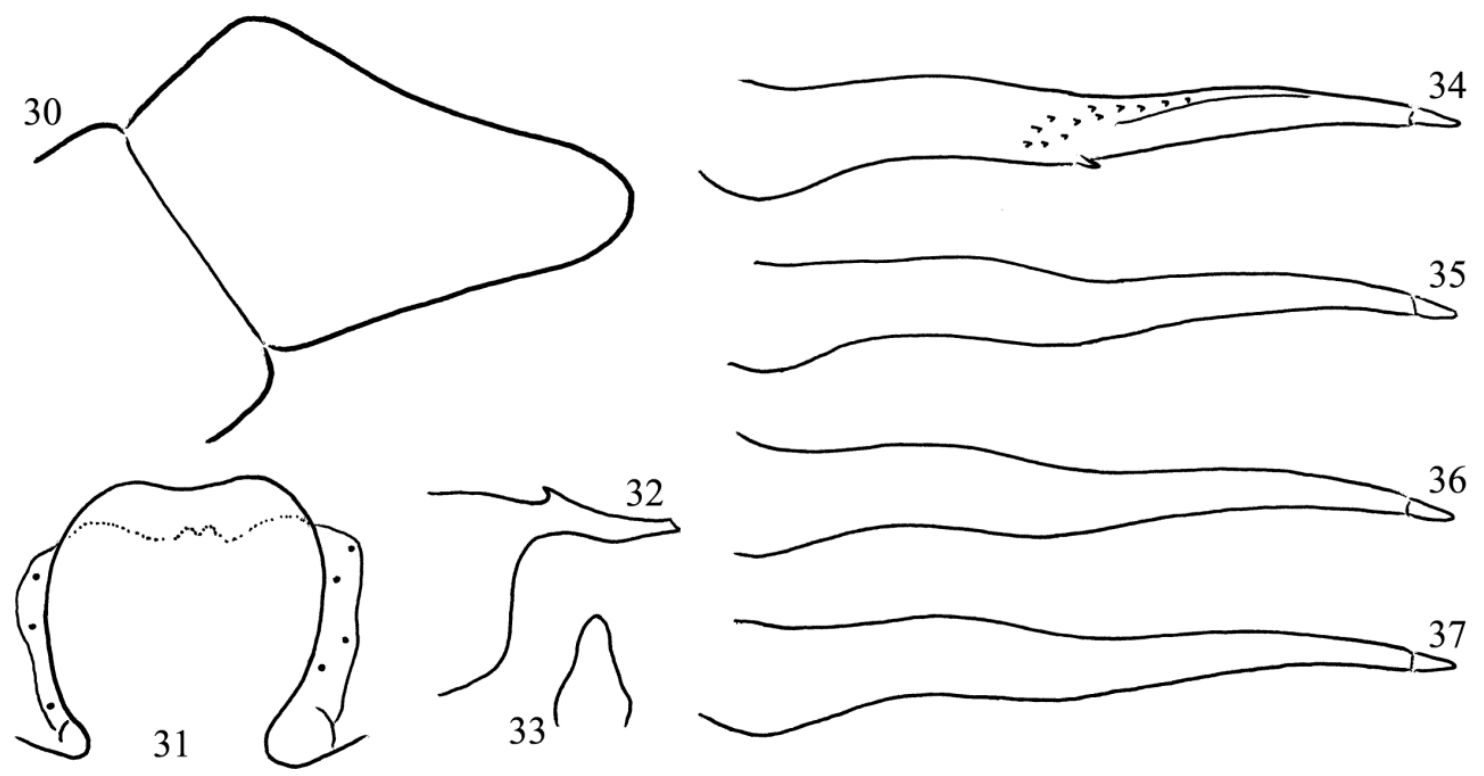

Figures 30-37. Rhyacophila csornahorensis Oláh \& Szczęsny, sp. nov. Holotype male: $30=$ left harpago in left lateral view, $31=$ dorsal process on tergite IX in dorsal view, $32=$ aedeagus in lateral view, $33=$ ventral process of the aedeagus in ventral view, $34=$ left paramere in lateral view, 35-37 = lateral profile of left paramere redrawn or drawn with slight viewing angle modification. 
Remarks. This new species is integrated probably in habitat isolation. There is a need to collect more specimens with exact habitat data and more study to recognize the variability ranges of both the neutral and adaptive characters. The single holotype has been collected in the same Chornohora Mts. whose streams are populated by $R$. matrensis sp. nov. The exact habitat of $R$. chornahorensis sp. nov. is not known.

\section{Rhyacophila denticulata McLachlan, 1879}

(Figures 38-46, 47-48)

Rhyacophila denticulata McLachlan, 1879:443:'Very similar in general appearance to the typical form of the next species.” (Rhyacophila fasciata). „Penissheaths very strongly and almost suddenly dilated and flattened in the basal portion, the lower edge of this dilatation furnished with numerous, rather strong, teeth or short spines.” „Pyrenees (Vallon de Burbe, near Juzet de Luchon, and near Cabanes du Portillon, Haute Garonne, June and July, Eaton, $14{ }^{\top}, 1$ ㅇ).”

Material examined. France, Department Haute-Garonne, Oô, les Granges d'Asteau Neste d'Oô, 1100 m, 26.X.2014, leg. G. Coppa (4 males,
OPC). France, Department Haute-Garonne, Oô, source Grange d'Astau, 1120 m, 18.VII.2018, leg. G. Coppa (1 male, 2 females; OPC). France, Department Ariège, Orlu, l'Ariège Anguils, $1138 \mathrm{~m}$, 23.X.2016, leg. G. Coppa (2 males, OPC). France, Department Ariège, Bethmale, le Balamet, 1002m, 11.VI.2006, leg. G. Coppa (1 female, OPC). France, Department Aude, Clermont-surLauquet, le Guinet, 324 m, 2.V.2012, leg. G. Coppa (1 male, OPC).

Re-diagnosis. Rhyacophila denticulata McLachlan was described from Department of Haute-Garonne, France. We have examined five male and one female specimens from the province of the Type Locality. We have collected and examined specimens with similar paramere organisation from the departments of Ariège and Aude. Our specimens from departments of PyrénéesAtlantiques and Hautes-Pyrénées with different paramere organisation belong to the new species Rhyacophila rova. Rhyacophila denticulata has subbasal region slender and longer, the ventrum of the expanded middle region with longer hump. The female of $R$. denticulata has the sclerite of segment VIII with bilobed ventral region in lateral view.
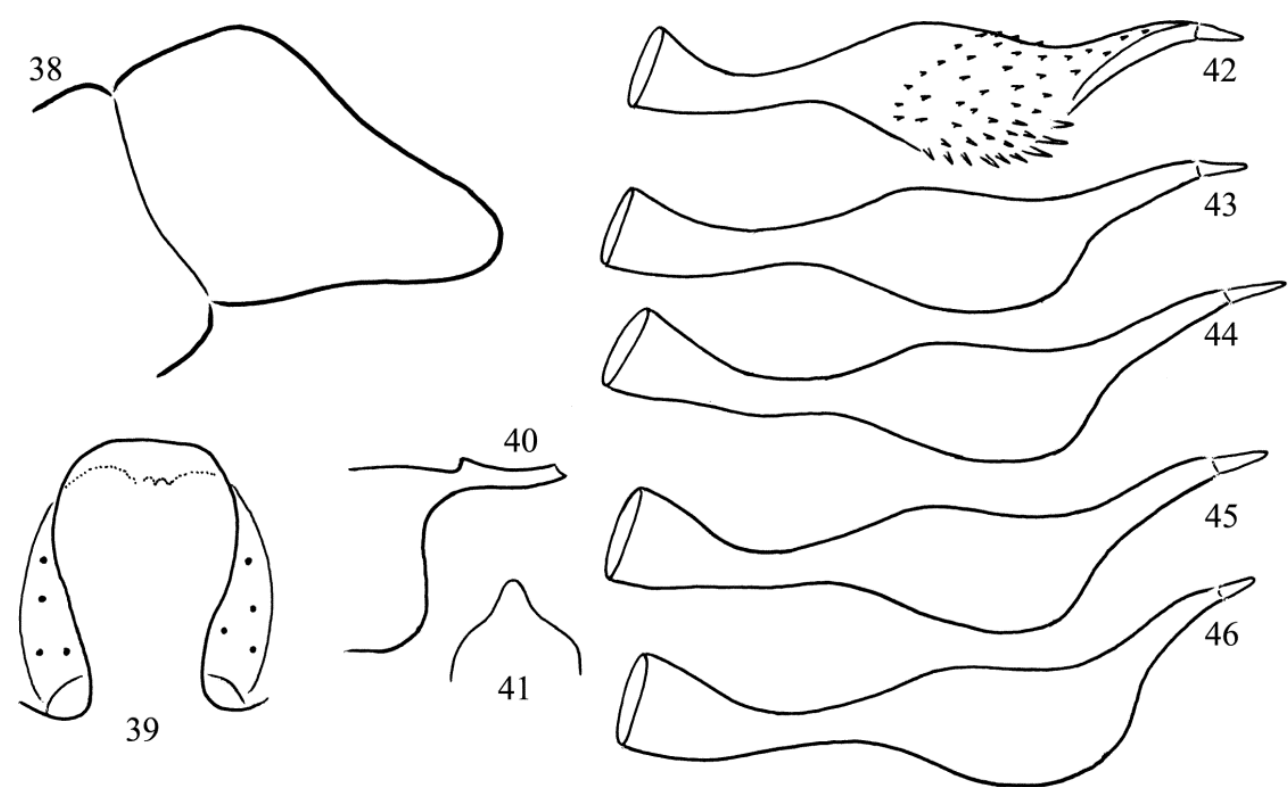

Figures 38-46. Rhyacophila denticulata McLachlan, 1879. Male: $38=$ left harpago in left lateral view, $39=$ dorsal process on tergite IX in dorsal view, $40=$ aedeagus in lateral view, $41=$ ventral process of the aedeagus in ventral view, $42=$ left paramere in lateral view, specimen from Haute-Garonne, 43 = lateral profile of left paramere, specimen from Haute-Garonne, 44-45= lateral profile of left paramere, specimens from Ariège, 46 = lateral profile of left paramere, specimen from Aude. 


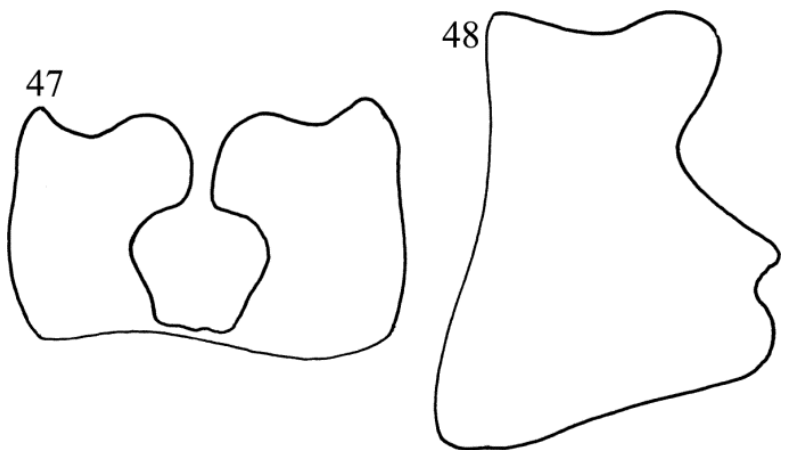

Figures 47-48. Rhyacophila denticulata McLachlan, 1879. Female from Haute-Garonne: $47=$ sclerites of segment VIII in dorsal view, $48=$ sclerites of segment VIII in lateral view.

\section{Rhyacophila fasciata Hagen, 1859}

(Figures 49-60, 61-64, 65-75, 76-87, 88-101, $102-111,112-123)$

Rhyacophila fasciata Hagen, 1859:153: „A. Appendices inferiores an der Spitze ungetheilt.” „I. Der zungenförmige Fortzatz des letzten Hinterleibsegments mit erweitertem Ende.” ,5. R. fasciata Hag. Die App sind der vorigen $\operatorname{Art}(R$. ferruginea Scop.) sehr ähnlich, doch ist die Grösse des Thiers viel beträchtlicher, und die Oberflügel haben drei dunkle Querbinden. Ein einzelnes Männchen aus Elberfeld."

Material examined. Albania, Librazhd Region, Shkumbini River Valley, near Qukes, 287m, N41.1458 E020.3766, 29.X.2018, leg. S. Beshkov \& A. Nahirnic (11 males, 8 females; OPC). Austria, Semmeringgebiet, Sonnwendstein, 2.VI. 1938, leg J. Sátori (3 males, OPC). Austria, Kärnten, St Lorenzen, 23.VI.2019, leg. W. Graf (1male, OPC). Croatia, Primorskogoranska Zupanija, Novi Vinodolski, 50-500 m, oak forest, netted with car at sunset, 22-27.VII.2006, leg. O. Merkl (1 male HNHM). Estonia, Lääne-Virumaa, Oostriku stream WGS84: N58.886, E26.047, 2. VI.2011, leg. J. Salokannel (2 males, 1 female, OPC). Finland, Kuusamo Putaanoja brook WGS84: N66.380, E29.425, 12.IX.2002, leg. J. Salokannel (1 male, 1 female; OPC). France, Department Aisne, Wimy, ru de Quiquengrone, 201 m, 4.VII.2016, leg. G. Coppa (1 male, OPC). France: Department Ardennes, Contreuve, ru de Cheppe, 118 m, 20.VII.2018, leg. G. Coppa (1 male, OPC). France, Department Ardennes, Elan, étang de Saint-Roger, 192 m, 15.IV.2007, leg. G. Coppa (2 males, 1 female; OPC). France, Department Ardennes, Hannogne-Saint-Martin, source Rouge-Cogneux, 210 m, 17.VII.2007, leg. G. Coppa (2 males, OPC). France, Department Aveyron, La Bastide-Pradines, le Cernon, $462 \mathrm{~m}$, 22.VII.2013, leg. G. Coppa (2 males, OPC). France, Department Aveyron, Sainte-Eulalie-deCernon, source du Cernon, 640 m, 25.VII.2013, leg. G. Coppa (3 males, 1 female; OPC). France, Department Haute-Saône, Fresse, ru de Chevestrage pont D97, 573 m, 1.V.2011 leg. G. Coppa (1 male, 2 females; OPC). France, Department Puyde-Dôme, Besse-et-Saint-Anastaise, cascade de Vaucoux, 890 m, 15.VII. 2007, leg. G. Coppa (1 male, OPC). France, Department Puy-de-Dôme, Chastreix, ru de Chambasse amont la Gerbodie, 1130 m, 28.X.2011, leg G. Coppa (3 males, 1 female; OPC). France, Department Puy-de-Dôme, Chastreix, ru de Chambasse amont la Gerbodie, 1130 m, 28.X.2011, leg. G. Coppa (1 male, OPC). France, Department Puy-de-Dôme, Picherande, pont ru de Chareire, $1171 \mathrm{~m}, 13$. VII.2007, leg. G. Coppa (1 male, OPC). France, Department Charente, Le Lindois, la Deguinie, 260 m, 27.X.2009, leg. G. Coppa (2 males, 1 female; OPC). France, Department Lozère, Cocures, le Briançon, Le Pont Colas, 600 m, 24.V.2017, leg. G. Coppa (2 males, 1 female; OPC). France, Department Corrèze, Saint-Merd, ru de Marly pont D78, $816 \mathrm{~m}$, 26.X.2011, leg. G. Coppa (1 male, 1 female; OPC). France, Department Nièvre, Saint-Brisson, aval Rocher du Chien sur la Cure, 27.IV.2008, leg. G. Coppa (5 males, 1 female; OPC). France, Department Nièvre, Glux-en-Glenne, l'Yonne, 700 m, 22.VII.2007, leg. G. Coppa (2 males, OPC). France, Department Nièvre, Arleuf, cascade près du Chatelet et sources, 14.IV.2004, leg. G. Coppa (1 male, OPC). France, Department Nièvre, Château-Chinon, sur l'Yonne en face Chatelet, 335 m, 16.IV.2004, (1 male, OPC). France, Department Doubs, Chatelblanc, bief Brideau, 10.VIII.2008, leg. G. Coppa (1 male, OPC). France, Department Tarn, le Verdoubre, Lacaune, 959 m, 21.VI.2014, leg. G. Coppa (1 male, OPC). France, Department Rhône, Propières, le Sornin pont D52, $900 \mathrm{~m}, 11$. VIII.2010, 

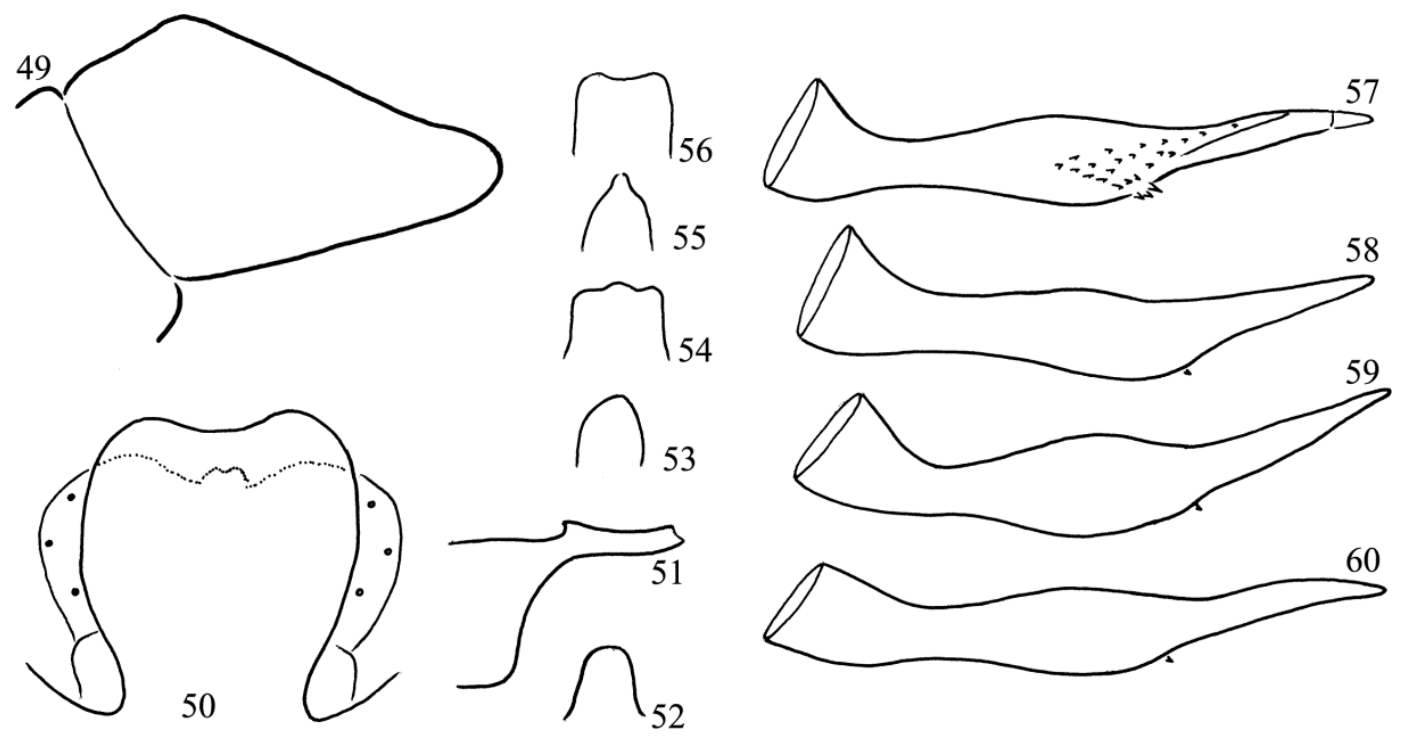

Figures 49-60. Rhyacophila fasciata Hagen, 1859. Male nearby Locus Typicus: $49=$ left harpago in left lateral view, $50=$ dorsal process on tergite IX in dorsal view, 51 = aedeagus in lateral view, 52-56 = variability of ventral process on the aedeagus in ventral view, population Börfink, Germany, 57 = left paramere in lateral view, specimen from Haute-Garonne, $58-60=$ lateral profile of left paramere, specimen from Börfink.

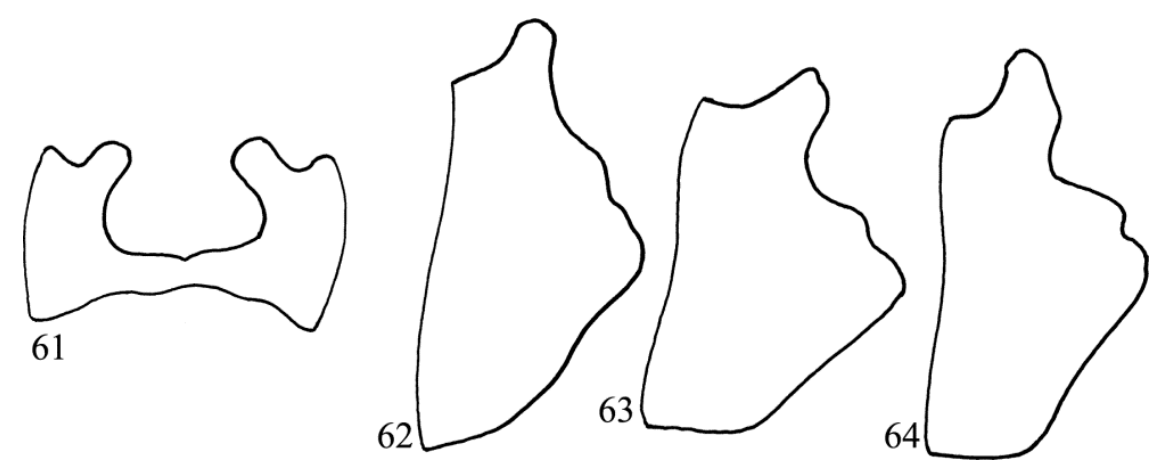

Figures 61-64. Rhyacophila fasciata Hagen, 1859. Females: 61 = sclerites of segment VIII in dorsal view, Börfink, Germany, $62=$ sclerites of segment VIII in lateral view, Börfink, Germany, 63 = sclerites of segment VIII in lateral view, Aisne Wimy, France, 64 = sclerites of segment VIII in lateral view, Saint Brisson, France.

leg. G. Coppa (1 male, OPC). Germany, Rheinland-Pfalz, 54310 Ralingen-Wintersdorf, Katzbachmündung, 49.7773, 6.5129, $150 \mathrm{~m}, 21$. VII. 2000, hand net leg. P.J. Neu (2 males, 2 females; OPC). Germany, Rheinland-Pfalz, Börfink, Ochsenfloßbach, 49.6915, 7.0705, 577 m, 30.V.2017, hand net leg. P.J. Neu (5 males, 5 females; OPC). Germany, Rheinland-Pfalz, 54636 Seffern, Glattbach, 50.0837, 6.4934, $330 \mathrm{~m}, 21$. VII.2000, at light leg. P.J. Neu (3 males, OPC). Germany, Buckow, Sophienfließ, 20.VI.1981, leg. F. Klima ( 2 males, OPC). Germany, Frankfurt an der Oder,
Heidekrug 1261, Stöbber, 20.VIII.1988, leg. F. Klima (1 male, 2 females, OPC). Germany, Frankfurt an der Oder, Heidekrug 1261, Stöbber, 18.VIII.1984, leg. F. Klima (1 male, 1 female, ZSM). Germany, Bavaria, obb. Westl. München, b. Langwied Bäche, Gvaslfinger Moos, 4.IX. 1995, leg. F. Foeckler (1 male, 2 females; ZSM). Germany, Bavaria, Murnaver Moos, Rothenbach Moorhof, 19.X.1994, leg. Burmeister (1 male, OPC). Germany, Bavaria, Ammersee, Seeholz, 8.VII.1991, leg. Utschik (1 male, ZSM). Germany Baden - Württemberg, Nürtingen, «im Rierth», 


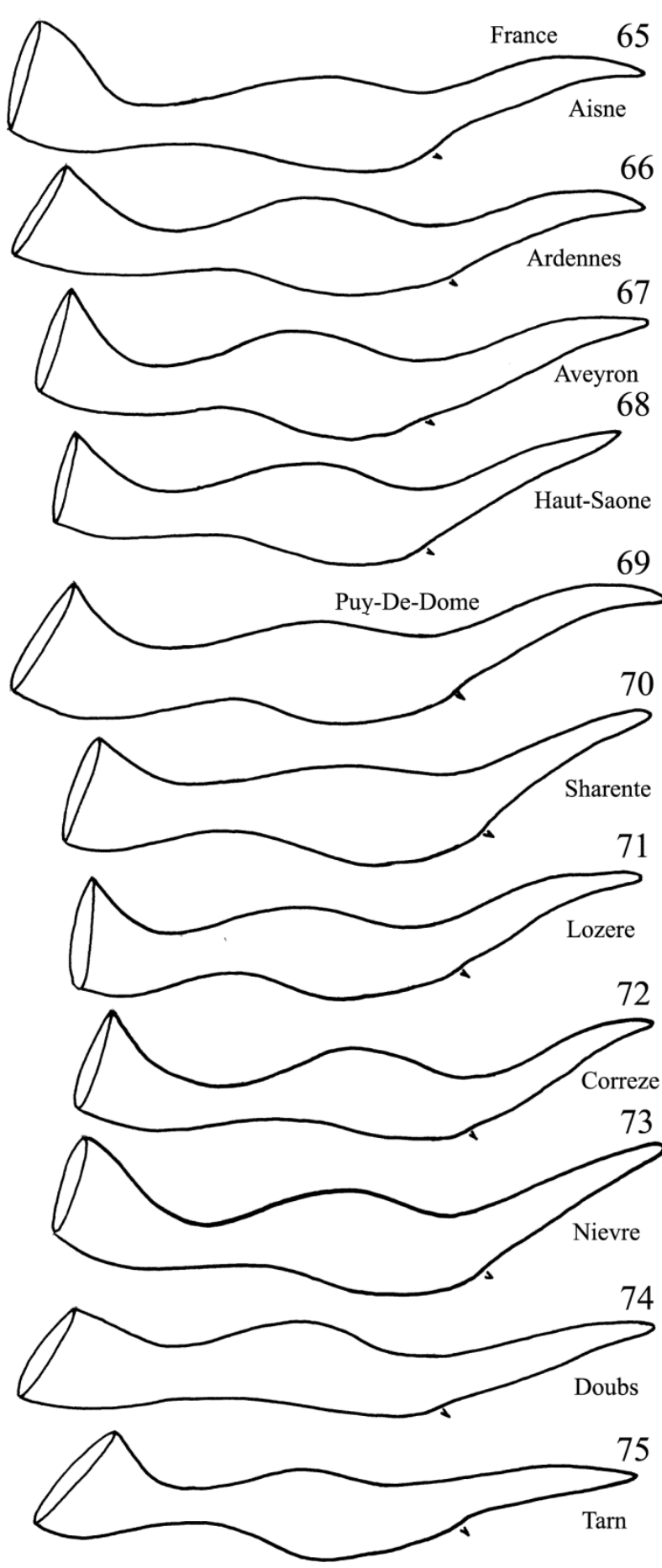

Figures 65-75. Rhyacophila fasciata Hagen, 1859. Lateral profile of paramere of specimens from provinces of France. The single spine symbol indicates the position of the group of large spines in order to demonstrate the length of the subterminal paramere shaft.

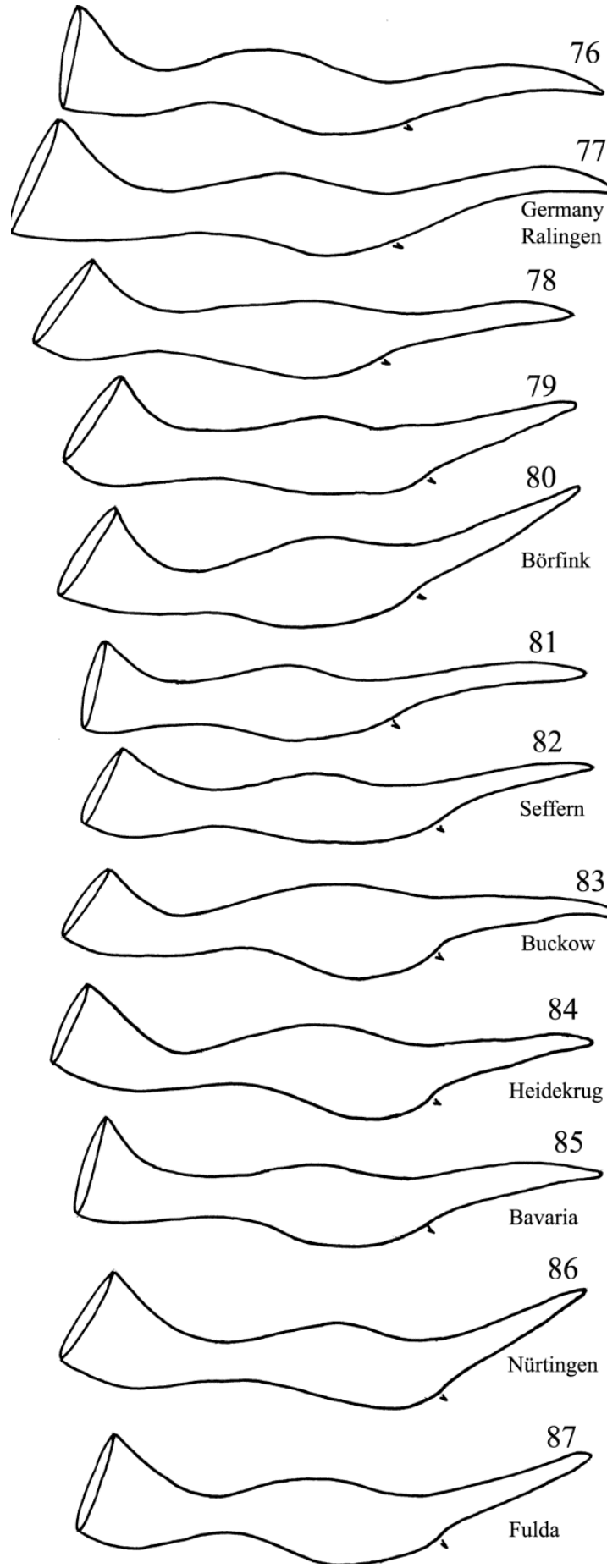

Figures 76-87. Rhyacophila fasciata Hagen, 1859. Lateral profile of paramere of specimens from various localities in Germany. The single spine symbol indicates the position of the group of large spines in order to demonstrate the length of the subterminal paramere shaft. 

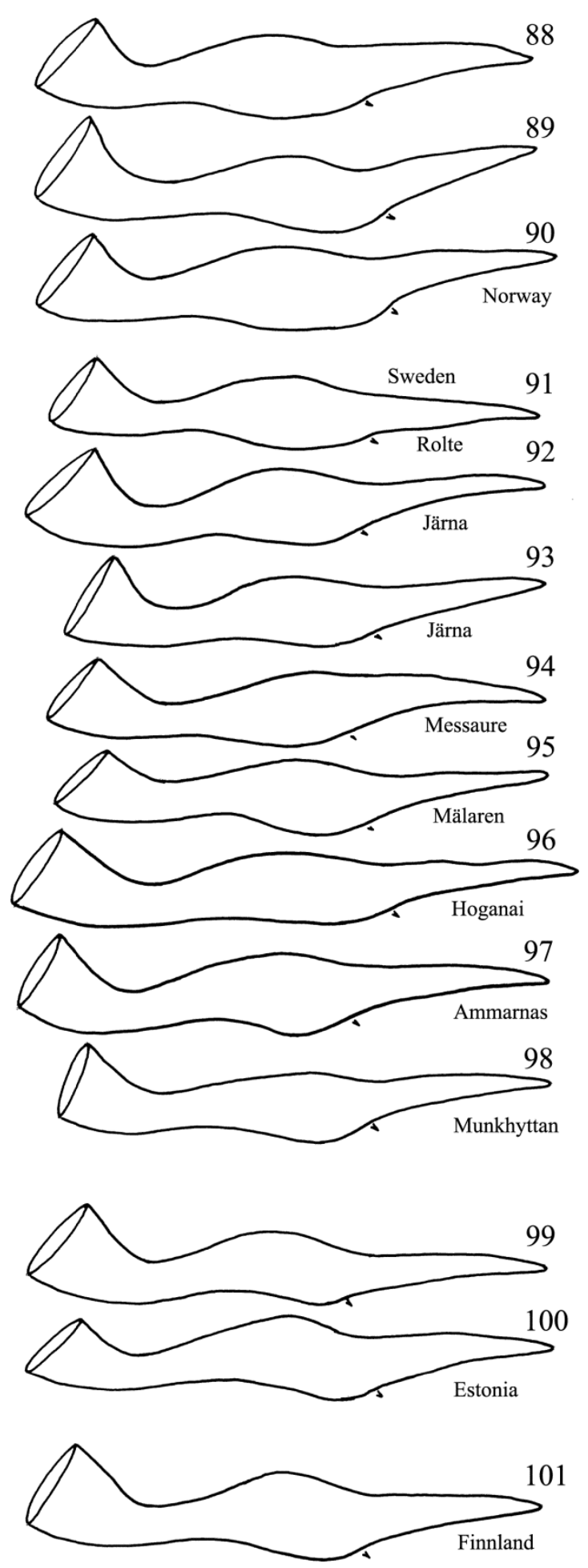

Figures 88-101. Rhyacophila fasciata Hagen, 1859. Lateral profile of paramere of specimens from Scandinavia: Norway, Sweden, Estonia, Finland. The single spine symbol indicates the position of the group of large spines in order to demonstrate the length of the subterminal paramere shaft.
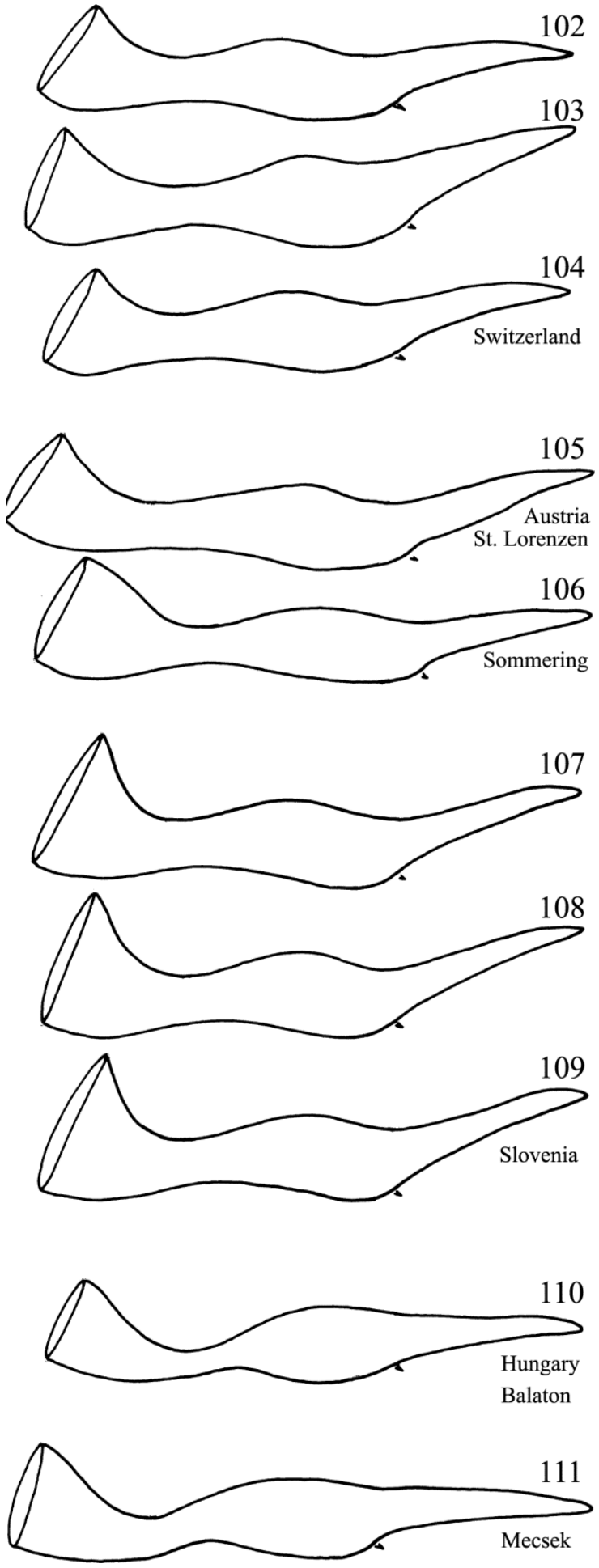

Figures 102-111. Rhyacophila fasciata Hagen, 1859. Lateral profile of paramere of specimens from Switzerland, Austria, Slovenia, Hungary. The single spine symbol indicates the position of the group of large spines in order to demonstrate the length of the subterminal paramere shaft. 


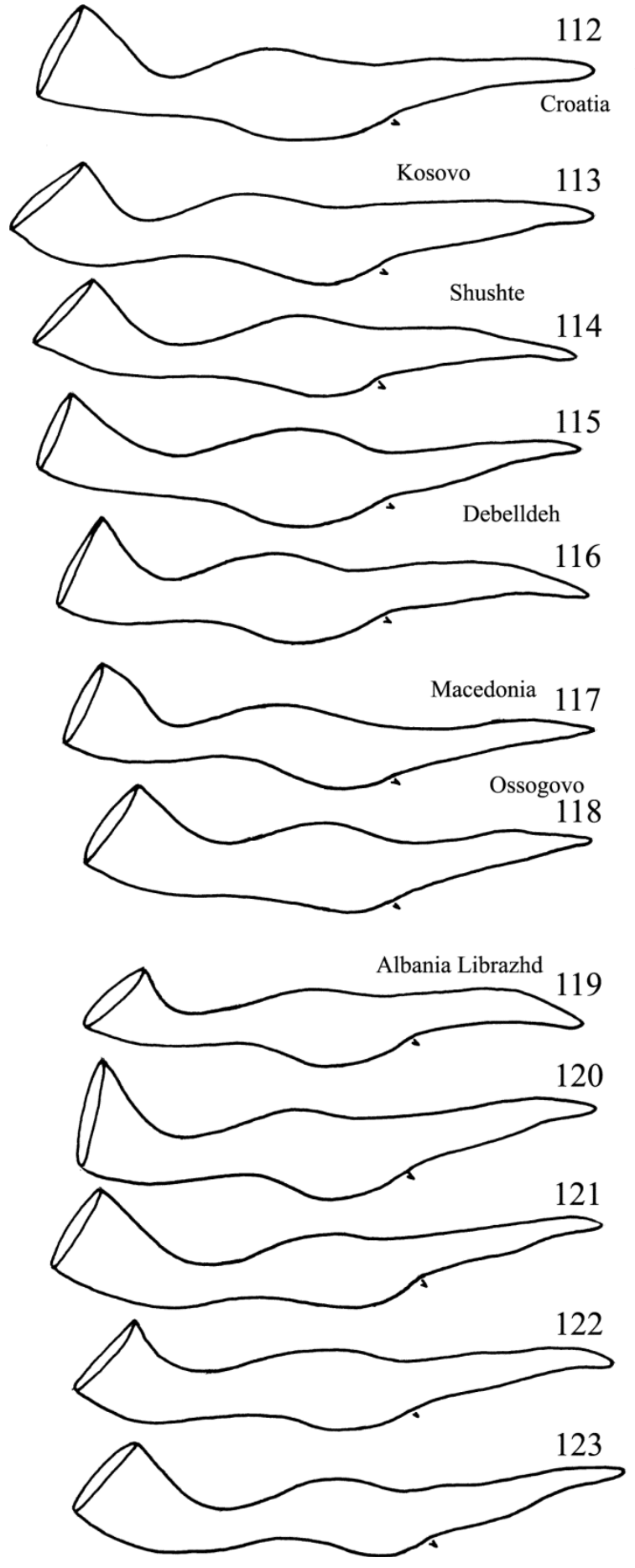

Figures 112-123. Rhyacophila fasciata Hagen, 1859. Lateral profile of paramere of specimens from Balkan Peninsula, Croatia, Kosovo, Macedonia, Albania. The single spine symbol indicates the position of the group of large spines in order to demonstrate the length of the subterminal paramere shaft.
1979, leg. Rieger (6 males, 5 females; 2 males, 1 female; OPC). Germany, Hessen, Schlitz, Fulda Flusstation, Breitenbach Gewächshause, 1995 (37 males, 35 females, ZSM; 6 males, 3 females; OPC). Hungary, Lake Balaton, Aszóföi Séd, 29.VIII.1983, singled by hand net, leg. J. Oláh (1 male, OPC). Hungary, Mecsek Mts., Iharos Kút spring, 2.VI.1988, singled by hand net, leg. J. Oláh (2 males, OPC). Kosovo, Shushtë, $42.28113^{\circ} \mathrm{N}, 21.35911^{\circ} \mathrm{E}, 573 \mathrm{~m}$ asl, 15.XI.2019, leg. H. Ibrahimi (3 males, OPC). Kosovo, Debelldeh, $42.25454^{\circ} \mathrm{N}, 21.40008^{\circ} \mathrm{E}, 982 \mathrm{~m}$ asl, 5.XI.2019, leg. H. Ibrahimi (4 males, OPC). North Macedonia, Yugoslav Macedonia, Ossogovo Mts, Istibanja Village, 17.VII.1979, leg. J. Ganev (2 males, NMNHS; 1 male, OPC). Norway, Telemark (TEY) Porsgrunn, Dammane, N59.0577 E9.6802, 12.VIII.1988 light trap leg. T. Andersen \& G. Søli (5 males, OPC). Slovenia, stream near Slovenska Bistrica, 25.VI.1988, singled by hand net, leg. J. Oláh (4 males, OPC). Sweden, SML, Jönköpings kommun, Röttle Stream, $57.99776^{\circ} \mathrm{N}, 14.43113^{\circ} \mathrm{E}, 3$. VIII.2012, light trap, leg. K.A. Johanson (1 male, SMNH). Sweden, SDML, Södertälje kommun, Järna, Moraån, immediately $\mathrm{S}$ bridge on $\mathrm{rd} 57$, $59.08257^{\circ} \mathrm{N}, 17.55221^{\circ} \mathrm{E}, 24$.VII.2012, light trap, leg. K.A. Johanson (2 males, SMNH). Sweden: Småland, Jönköping Kommun, Girabäcken Naturreservat, at Lake Vättern, 58.070069N, $14.500794^{\circ} \mathrm{E}$, light trap, 1.VI.2014. leg K.A. Johanson (1 male, SMNH). Sweden, Lappland, Jokkmokks kommun, NE Messaure, small lake at Högträsk, $66.6634^{\circ} \mathrm{N}, 20.5857^{\circ} \mathrm{E}$, sweep net, 5.VIII.2015, leg. K.A. Johanson (1 male, SMNH). Sweden, Södertälje kommun, Mälaren, $59.2164^{\circ} \mathrm{N}, 17.6107^{\circ} \mathrm{E}$, light trap, 15.VIII.2012, leg. K.A. Johanson (1 male, SMNH). Sweden, Skåne, Höganäs kommun, shallow pond near sea shore, $56.2713^{\circ} \mathrm{N}, 12.5068^{\circ} \mathrm{E}, 28 . \mathrm{VIII} .2016$, net, leg. KA Johanson (1 male, SMNH). Sweden, Lapland, Sorsele kommun, Ammarnäs, $65.944^{\circ} \mathrm{N}$, $16.245^{\circ} \mathrm{E}, 430 \mathrm{~m}$, net, stream with dense vegetation along banks, 19:00-21:00 h, 5.VIII. 2019, leg. K.A. Johanson \& M. Peyrard (1 male, SMNH). Sweden, Västmanland, Lindesberg kommun, Munkhyttan naturreservat, Munkhyttebäcken, $59.606307^{\circ} \mathrm{N}, 15.131736^{\circ} \mathrm{E}, \quad 16 . \mathrm{VI}$. 
2014, leg. K.A. Johanson (1 male, SMNH). Switzerland, Appenzell Innerrhoden Canton, Hüte, Bach Beichersweid, $1180 \mathrm{~m}, 47^{\circ} 18^{\prime} 28.4^{\prime \prime} 9^{\circ} 28^{\prime}$ 16.8", 4.VII.2006, leg. V. Lubini (10 males, 6 females; OPC).

Re-diagnosis. Having large spines and with lateral location of longitudinal band of microtrichia Rhyacophila. fasciata Hagen belongs and is the nominate species of $R$. fasciata lineage, as well as having short subterminal paramere shaft it is a member of $R$. fasciata clade of species. The general pattern of the paramere is most close to $R$. matrensis sp. nov., but differs by having lateral profile of the left parameres short subterminal or post spine shaft. The female of $R$. fasciata has the sclerite of segment VIII with variously bilobed middle region in lateral view. $R$. denticulata has similarly bilobed apical region but more ventrad. The dorsomesal lobes of sclerite VIII is smaller and slender at $R$. fasciata and larger and robust at $R$. denticulata.

Distribution. Rhyacophila fasciata has a large range from France (almost all provinces except Pyrenees) through Switzerland, Germany, Austria in northern direction to Norway, Sweden, Finland, Estonia, as well as in southern direction to Italy, Slovenia, Croatia, Kosovo, Macedonia, Albania. Its taxonomic position in England and Greece need to be re-examined.

Variability. The character state of the short, abbreviated subterminal paramere shaft seems very stable in all of the examined populations from France North to Finland and South to Albania. The variability of the character state of the neutral ventral lobe on the aedeagus was examined in the near Locus Typicus German population and it was extremely high. We have recorded similarly large shape variability in ventral lobe of the aedeagus in the $R$. sp. 3 (to be described in Oláh et al. 2020), a member of the Rhyacophila mysica lineage.

Relations. Based on the character state of distribution, $R$. fasciata is the probable ancestral species of the clade of species with abbreviated subterminal paramere shaft as well as the probable ancestral species of $R$. matrensis sp. nov., the ancestral species of the clade of species with elongated subterminal paramere shaft. It is very common and abundant along streams of various types and new sibling species have been split either in habitat isolation of spring and spring stream ( $R$. ferda, R. ruda, R. salfa) or in geographic isolation ( $R$. suna).

\section{Rhyacophila ferda Oláh, sp. nov.}

(Figures 124-131)

Material examined. Holotype: Bosnia \& Herzegovina, Drinjaca, small spring stream, 44.281161 19.146632, 31.VIII.1988, singled leg. J. Oláh (1 male, OPC).

Description and diagnosis. Head, antennae, maxillary palps, legs and segmental sclerites dark brown. Forewing brown mottled with pale spotted reticulation, very faded in alcohol, forewing length $14 \mathrm{~mm}$. Dorsal shape of the apicodorsal process of segment IX slightly elongated with broad neck. Lateral shape of the harpago, the second segment of the gonopods obliquely truncate with longer ventrum. The lateral profile of the aedeagus horizontal, rather slim. The ventral shape of the ventral process on the aedeagus broad. The lateral profile of the left paramere with long subbasal and short subterminal regions and with short and oblique middle region.

Having large spines and with lateral location of longitudinal band of microtrichia Rhyacophila. ruda sp. nov, belongs to the $R$. fasciata lineage, as well as having short subterminal paramere shaft it is a member of $R$. fasciata clade of species. The general pattern of the paramere is most close to $R$. fasciata Hagen, but differs by having short and obliquely directed middle region.

Etymology. ferda, coined form "ferde" oblique, slant in Hungarian, refers to the shape of the middle expanded middle region on the paramere. 


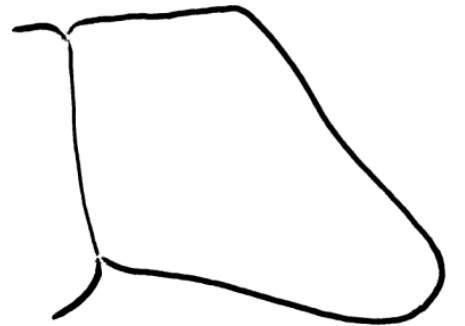

124

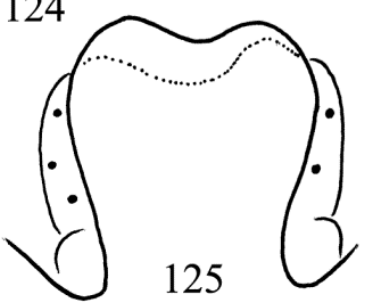

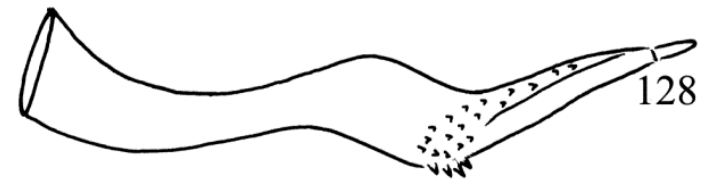

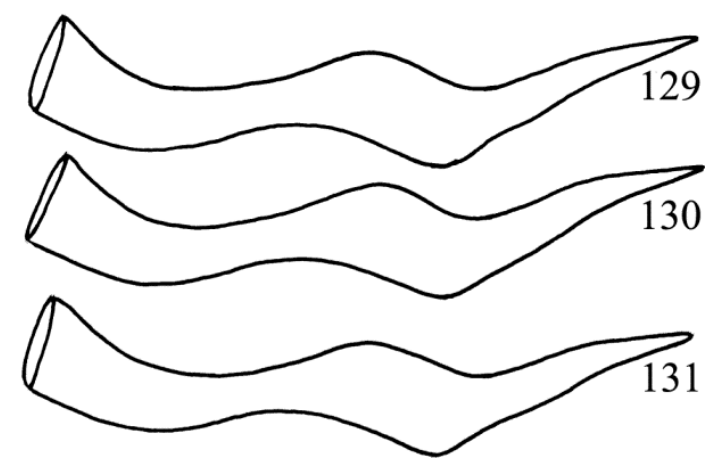

Figures 124-131. Rhyacophila ferda Oláh, sp. nov. Holotype male: $124=$ left harpago in left lateral view, $125=$ dorsal process on tergite IX in dorsal view, $126=$ aedeagus in lateral view, $127=$ ventral process of the aedeagus in ventral view, $128=$ left paramere in lateral view, 129-131 = lateral profile of left paramere redrawn or drawn with slight viewing angle modification.

\section{Rhyacophila gemella Navas, 1923 stat. rest.}

Rhyacophila gemella Navas, 1923:21-22: „valvis copulatoris ferrugineis, desuper visis arcuatis, sensim acuminatis, ad apicem contiguis; a latere visis seclivibus, margine superiore et inferiore sinuoso; copulatore multo breviore, apice a latere viso sagittiformi seu hamiformi." „Patria. Oris (Barcelona), 14 de julio de 1922 (Col. m.).”

Rhyacophila denticulata McLachlan, 1879: Schmid, F. 1970: 120 synonymized with.

Remarks. Valladolid et al. (2018: 530) stated that "After a systematic search at University of Zaragoza and at Museo de Ciencias Naturales of Barcelona it was concluded that the single type specimen has been lost".

Based on the original description and drawings and compared with the original drawings and the examined and drawn specimens of its sibling Rhyacophila sociata Navas, 1916 described from Spain, Cantabria as well as considering the character state of the distribution principle we reinstate its species status. However, to establish its more precise relation inside the Rhyacophila sociata clade we have to collect this interesting species from the locus typicus at Oris (southwards Borgonyà) nearby Barcelona.

\section{Rhyacophila kopasa Oláh \& Coppa, sp. nov.}

(Figures 132-138)

Material examined. Holotype: France, Department Ariège, Auzat, torrent Picot, aval barrage Soulcem, 1354m, 16.V.2015, leg. G. Coppa (1 male, OPC).

Description and diagnosis. Head, antennae, maxillary palps, legs and segmental sclerites dark brown. Forewing brown mottled with pale spotted reticulation, very faded in alcohol, forewing length $12 \mathrm{~mm}$. Dorsal shape of the apicodorsal process of segment IX elongated subquadrangular. Lateral shape of the harpago, the second segment of the gonopods obliquely truncate with longer ventrum. The lateral profile of the aedeagus horizontal rather slim. The ventral shape of the ventral process on the aedeagus broad basad with narrowing apex. The lateral profile of the left paramere with extremely elongated middle broadening dilatation; the longitudinal band of the short microtrichia located laterad and restricted to the ventrum

Having large spines and with lateral location of longitudinal band of microtrichia $R$. kopasa sp. 

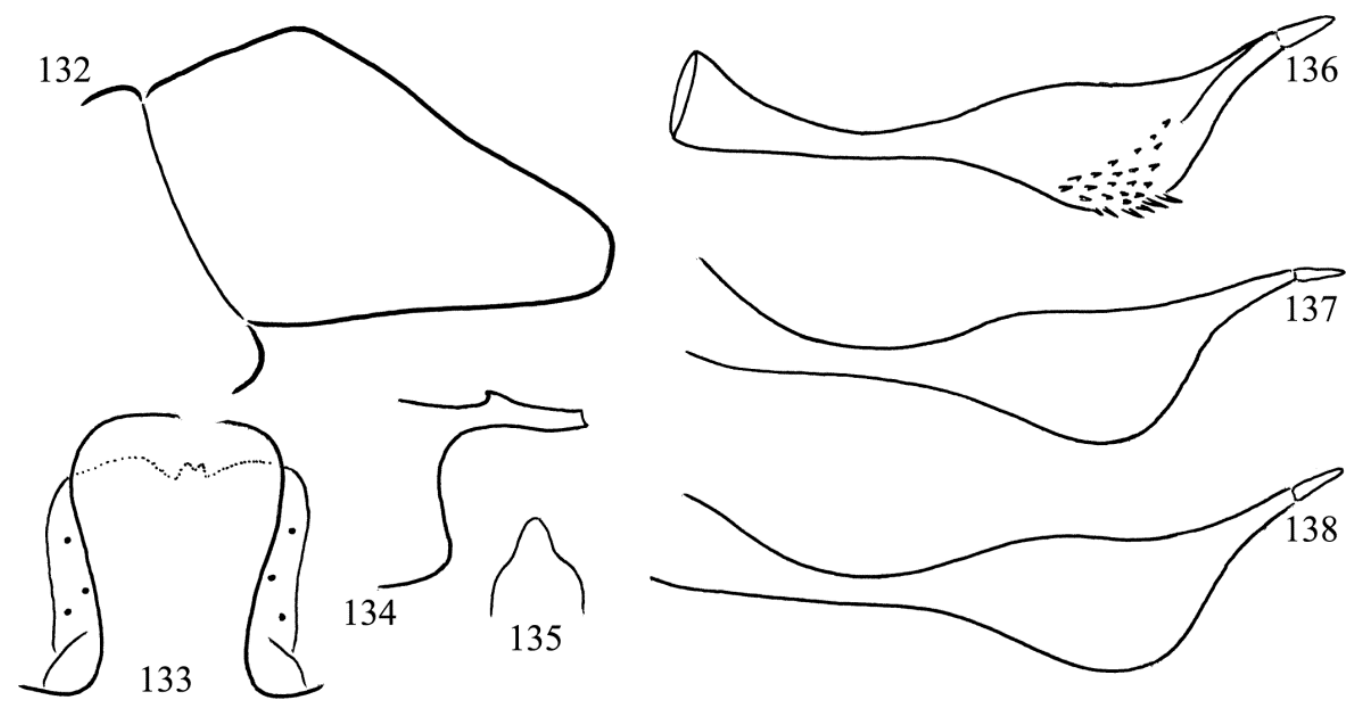

Figures 132-138. Rhyacophila kopasa Oláh \& Coppa, sp. nov. Holotype male: $132=$ left harpago in left lateral view, $133=$ dorsal process on tergite IX in dorsal view, 134 = aedeagus in lateral view, $135=$ ventral process of the aedeagus in ventral view, $136=$ left paramere in lateral view, 137-138 = lateral profile of left paramere redrawn or drawn with slight viewing angle modification.

nov. belongs to the Rhyacophila fasciata lineage. It is distinguished in the fasciata lineage by the following combination of character states: the ventral extension of the aedeagus has a simple almost vertical lateral profile; several large spines on the paramere ventrum; lateral profile of the paramere with rather flat middle dorsum, without high hump. With this character combination $R$. kopasa sp. nov. belongs to the $R$. denticulata clade and most close to $R$. denticulata, but differs by having microtrichial band on the paramere very reduced; the region above the longitudinal ridge is completely free of any kind of microtrichia as well as on the middle broadening the microtrichial band is restricted to the ventrum.

Etymology. kopasa, form "kopasz" bald, bare or naked in Hungarian, refers to the almost total disappearance of the microtrichia on the dorsal region of the middle expansion of the paramere.

\section{Rhyacophila kykladica Malicky \& Sipahiler, 1993}

Rhyacophila fasciata kykladica Malicky \& Sipahiler, 1993:462: "Holotypus $\widehat{o}^{\Uparrow}$ : Euböa, Ochi-Gebirge, Komiton, 6.6.1979. Paratypen: do., Ag. Dimitrios,

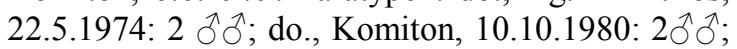

Andros: Apikia, 29.5.1973:2 $\widehat{\jmath}$, Zahlreiche weitere Paratypen von mehreren Plätzen auf der Insel Andros und aus dem Ochi-Gebirge auf Süd-Euböa". "Diese Unterart ist offenbar ein KykladenEndemit."

Rhyacophila kykladica Malicky \& Sipahiler, 1993: Valladolid et al. 2019: 518, the subspecies status was raised to species rank based on morphological and genetical data.

\section{Rhyacophila matrensis Oláh \& Szczęsny, sp. nov.}

(Figures 139-146, 147-150, 151-156, 157-165, 166-177, 178-188, 189-196, 197-205)

Material examined. Holotype: Hungary, Mátra Mts., Mátraszentimre, Csörgő stream, 6.VIII. 1973, singled by hand net, leg. J. Oláh (1 male, OPC). Paratypes: Czech Republic, W Bohemia, Krušné hory Mts., Tatrovická stoka brook nr. Vřesová $(480 \mathrm{~m}), 15 . V .-12 . V I I I .2002$, (Malaise trap) leg. P. Chvojka (12 males, 4 females, OPC; 38 males, 16 females,NMPC). Czech Republic, N Bohemia, Jizerské hory Mts., Jedlový důl, VI.IX.2005, (Malaise trap) leg. J. Preisler \& P. Vonička (8 males, OPC; 24 males, NMPC). Czech Republic, E Moravia; Bílé Krapaty Mts., 

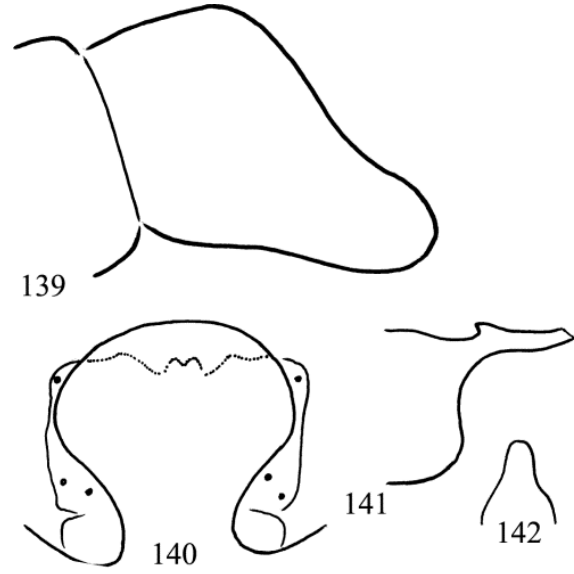
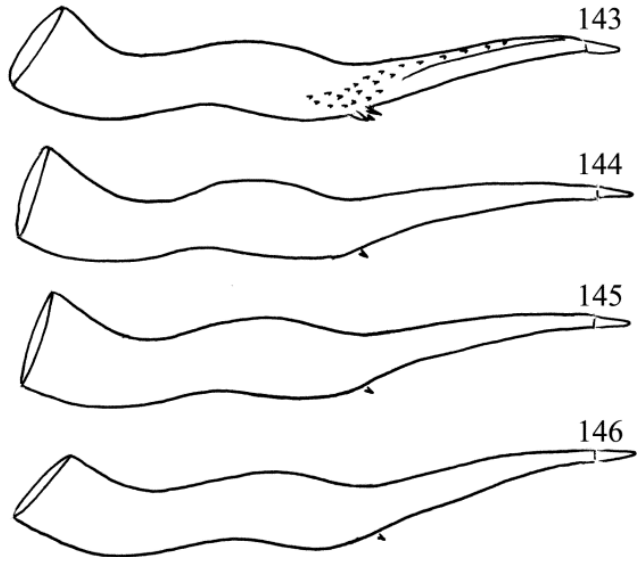

Figures 139-146. Rhyacophila matrensis Oláh \& Szczęsny, sp. nov. Holotype male: $139=$ left harpago in left lateral view, $140=$ dorsal process on tergite IX in dorsal view, $141=$ aedeagus in lateral view, $142=$ ventral process of the aedeagus in ventral view, 143 = left paramere in lateral view, 144-146 = lateral profile of left paramere redrawn or drawn with slight viewing angle modification.
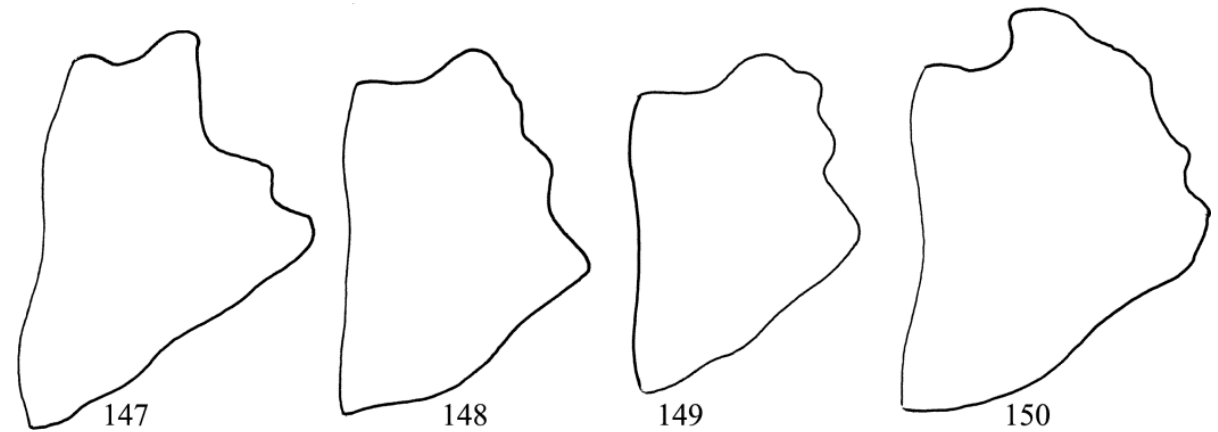

Figures 147-150. Rhyacophila matrensis Oláh \& Szczęsny, sp. nov. Females: $147=$ sclerites of segment VIII in lateral view, Bükk, Hungary, $148=$ sclerites of segment VIII in lateral view, W. Bohemia, Czechia, $149=$ sclerites of segment VIII in lateral view, Polana Bialego Potoka, Tatra, Poland, 150=sclerites of segment VIII in lateral view, Chocholowska Valley, Tatra, Poland.

Velička stream (480-700 m), VI.2005, leg. P. Chvojka (3 males, 1 female, OPC; 6 males, 2 females; NMPC). Germany, DDR (East Germany), Thuringia, Suhl district, 6086 Pappenheim, Langer Bach, 12.VII.1986, leg. F. Klima (1 male, 1 female; OPC). Germany, DDR (East Germany), Thuringia, Suhl district, 6086 Pappenheim, Langer Bach b., 7.VIII.1985, leg. F. Klima (1 male, phallic organ lacking; ZSM). Germany, DDR (East Germany), Thuringia, Suhl district, 6086 Pappenheim, Ickers Bach, 18.VI.1988, leg. F. Klima (1 male, 1 female; ZSM). Germany, Dresden Dristrict, Berthelsdorf 8352 LF, Rückenberg, Klunber, 6-7.VII.1987, leg. T. Karisch (2 males, 2 females, ZSM; 2 males, OPC). Hungary, Jósvafö, Ménes stream, 5.VII.
1983, singled by hand net, leg. J. Oláh ( 3 males, 1 female; OPC). Hungary, Bükk Mts. Garadna stream, 8.VII.1983, singled by hand net, leg. J. Oláh (2 males, 3 females; OPC). Hungary, Zempléni Mts. Telkibánya, 25.V.1982, lighleg. J. Oláh (8 males, 1 female; OPC). Poland, High Tatra Mts., Polana Bialego Potoka, 20-21.VIII. 2009, singled leg. J. Oláh (2 males, 1 female, OPC). Poland, High Tatra Mts., Chocholowska Valley, 22.VIII.1986, singled leg. J. Oláh (1 female, OPC). Poland, Jura-Kraków-Częstochowa Upland, vicinity of Ojców National Park, leg. B. Szczęsny (3 males, OPC). Poland, West Carpathian Mountains, Babia Góra Mt. 700-1200 m, leg. B. Szczęsny (5 males, 5 females; OPC). Poland, East Carpathian Mountains. Bieszczady 

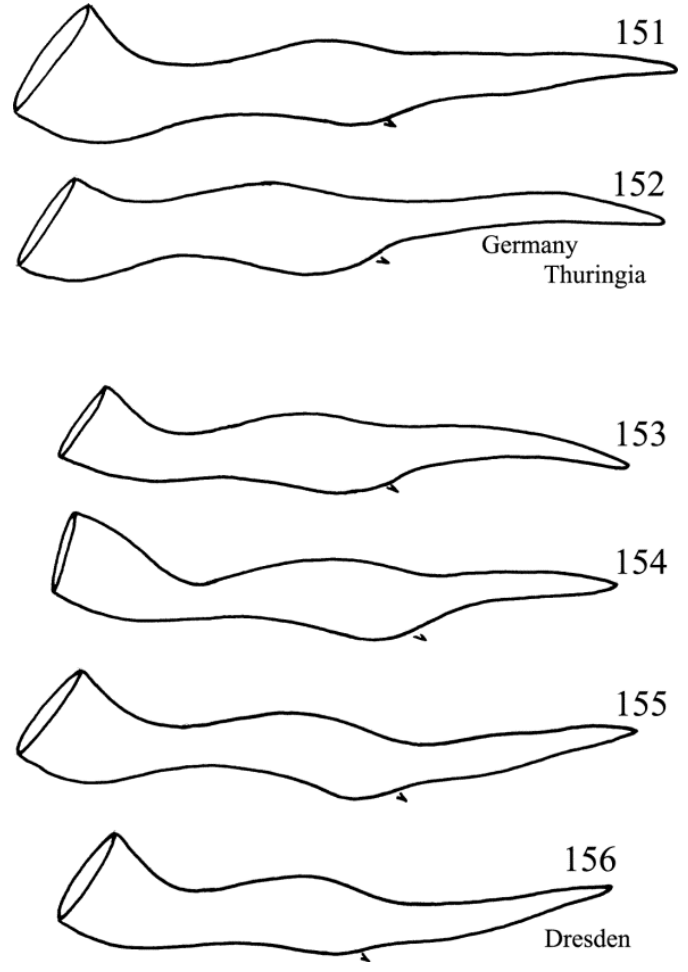

Figures 151-156. Rhyacophila matrensis Oláh \& Szczęsny, sp. nov. Lateral profile of paramere of specimens from Germany. The single spine symbol indicates the position of the group of large spines in order to demonstrate the length of the subterminal paramere shaft. Note the variation in the length of the subterminal paramere shaft at the Dresden population.

Mts, 600-1100m, leg. B. Szczęsny (5 males, 5 females; OPC). Poland, West Carpathian Mts., Tatra Mts, 1000-1300m, leg. B. Szczęsny (4 males, 4 females; OPC). Romania, Maramureş county, Muntii Ignis, Deseşti-Stațiunea Izvoare, open stream on the Valhani Plateau, $940 \mathrm{~m}$, N47²43.945', E23ํ⒋661', 08.10.2010, leg. P. Barcánfalvi, D. Murányi \& J. Oláh, (1male, OPC). Slovakia, Tatralomnic, 17.VII.1966, light, leg. J. Oláh (1 male, OPC). Slovakia, N Slovakia, Western Beskids, brook below Babia hora Mt. (1000-1300 m), 15.X.1991, leg. P. Chvojka (1 male, 1 female, OPC; 6 males, 1 female, NMPC). Slovakia, W Slovakia, Strážovské vrchy Mts., Domanižanka brook (360 m), 27.VI.2009, leg. P. Chvojka (3 males, OPC; 8 males, NMPC). Slovakia, N Slovakia, Chočské vrchy Mts., Kvačianka brook, 2.VII.1992, leg. P. Chvojka (2 males, OPC; 7 males, 1 female, NMPC). Slo- vakia, N Slovakia, High Tatras, Hincov stream (1640 m), 12.X.1988, leg. P. Chvojka (1male, 1 female, OPC; 2 males, 2 females, NMPC). Slovakia, N Slovakia, Tatra foothills, Skalný brook nr. Nová Lesná $(740$ m), 4.VII.1989, leg. P. Chvojka (1male, OPC; 1 male, NMPC). Slovakia, N Slovakia, Spišská Magura Hills, brook below Jezerské lake (770 m), 1.VII.1989, leg. P. Chvojka (1 male, OPC; 1 male, NMPC). Slovakia, C Slovakia, Muránská planina Mts., Trsteník brook nr. Salašná, 20.VII.1999, leg. P. Chvojka (3 males, OPC; 7 males, 1 female; NMPC). Slovakia, Banskobystrický region, Javorie Mts, Stará Huta, Blýskavica, Tisovník Stream, N4827.553' E19¹8.048', 671m, 7-9.X.2013, singled leg. J. Oláh \& L. Szél (109 males, 57 females, OPC). Banskobystrický region, Javorie Mts, Stará Huta, Blýskavica, Stara Rieka Stream, N4825.248' E19¹7.822', 764m, 7-9.X.2013, singled leg. J. Oláh \& L. Szél, (1 male, OPC). Ukraine, East Carpathians, Uholka Mała brook, 410m, NE-Carpathians Krasna range, Uhla Nature Reserve, mountainous primary forest, 20.VII. 2008, light trap, leg. B. Szczęsny (2 males, OPC). Ukraine, East Carpathians, Gorgany range, Bystritza river at Bystrietz, 700m, 19.X.2001, light trap, leg. B. Szczęsny (1 male, OPC). Ukraine, East Carpathians, Chornohora Mts., Breskulec brook, 1000-1400m, 8.X.2005, leg. B. Szczęsny (3 males, OPC). Ukraine, Bieszczady Mts (Beszszádok), Ung National Park, above Lubnya (Kiesvölgy), N: 4902' 13,90” E: 2242' 59,75”, 579 m, 20. IX. 2013, singled by sweep net, leg. J. Oláh, Cs. Balogh, Cs. Deák \& I. Meszesán (1 male, OPC).

Description and diagnosis. Head, antennae, maxillary palps, legs and segmental sclerites medium brown. Forewing brown mottled with pale spotted reticulation, very faded in alcohol, forewing length $13 \mathrm{~mm}$. Dorsal shape of the apicodorsal process of segment IX almost circular with narrow neck. Lateral shape of the harpago, the second segment of the gonopods obliquely truncate with longer ventrum. The lateral profile of the aedeagus horizontal, rather slim. The ventral shape of the ventral process on the aedeagus elongated with broader base and round- 

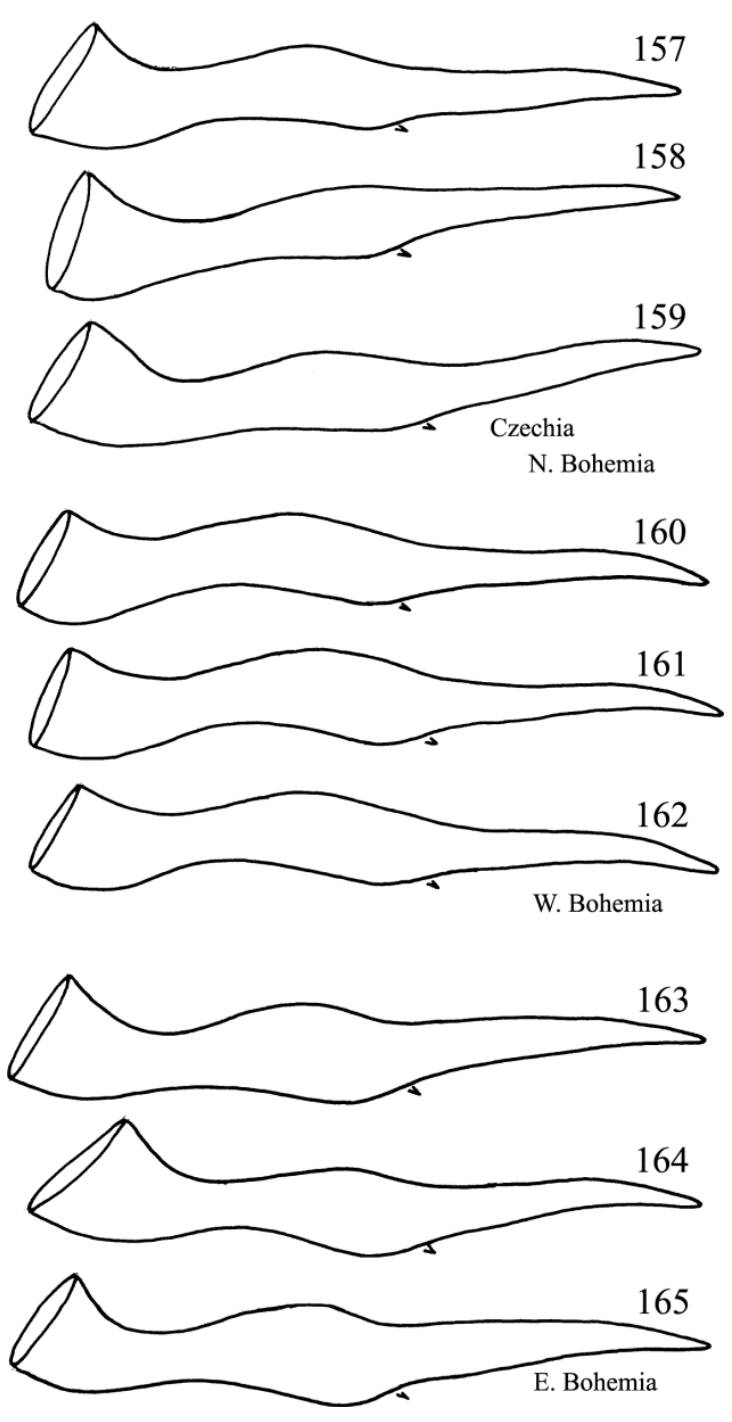

Figures 157-165. Rhyacophila matrensis Oláh \& Szczęsny, sp. nov. Lateral profile of paramere of specimens from Czechia. The single spine symbol indicates the position of the group of large spines in order to demonstrate the length of the subterminal paramere shaft.

ed head. The lateral profile of the left paramere with extended basal region, stout subbasal region and slightly expanded middle region; the longitudinal band of the short microtrichia located laterad and accompanied with a small group of large spines.

Having large spines and with lateral location of longitudinal band of microtrichia $R$. matrensis sp. nov. belongs to the Rhyacophila fasciata lineage, as well as having long subterminal paramere shaft it is the nominate member of $R$. matrensis clade of species and most close to $R$. csornahorensis sp. n., but differs by having lateral profile of the left paramere with expanded basal, constricted subbasal and expanded middle regions, not digitate and armed with a group of large spines, not only with a single one. The circular dorsal process of segment IX with narrow neck seems different.

Etymology. Named after the mountain region of the type locality.

Remarks. Rhyacophila matrensis sp. nov. has a large distributional area from Germany (Thuringia) through Czech Republic, Poland, Slovakia, Hungary, Ukraine, to Romania (Maramures Mts.). Its speciation was realised by integrative organisation of the subterminal elongation of the paramere shaft, the paramere region between the ventrally located groups of large spines and the modified terminal seta. This character state seems very stable in all of the examined populations from Thuringia (Germany) to Maramures Mts. (Romania). We have recorded discernible variability in the length of subterminal shaft only in a single population: Germany, Dresden Dristrict, Berthelsdorf.

Based on the character state of distribution, $R$. matrensis is the probable ancestral species of the clade of species with elongated subterminal paramere shaft. It is very common and abundant along streams of various types and new sibling species have been split either in habitat isolation of spring and spring stream ( $R$. zemplenensis, $R$. csornahorensis) or in geographic isolation $(R$. biharensis, $R$. retezatensis, $R$. bulgarica).

\section{Rhyacophila retezatensis Oláh, sp. nov.}

(Figures 206-213)

Material examined. Holotype: Romania, Retezat Mts, Riu Barbat, 1090 m, 45.387 23.043, 31.V.2007, leg. M. Bálint (1 male, OPC). Paratypes: same as holotype (1 male, OPC). Romania, Sibiu county, Făgăraş Mts, Cârțişoara, 

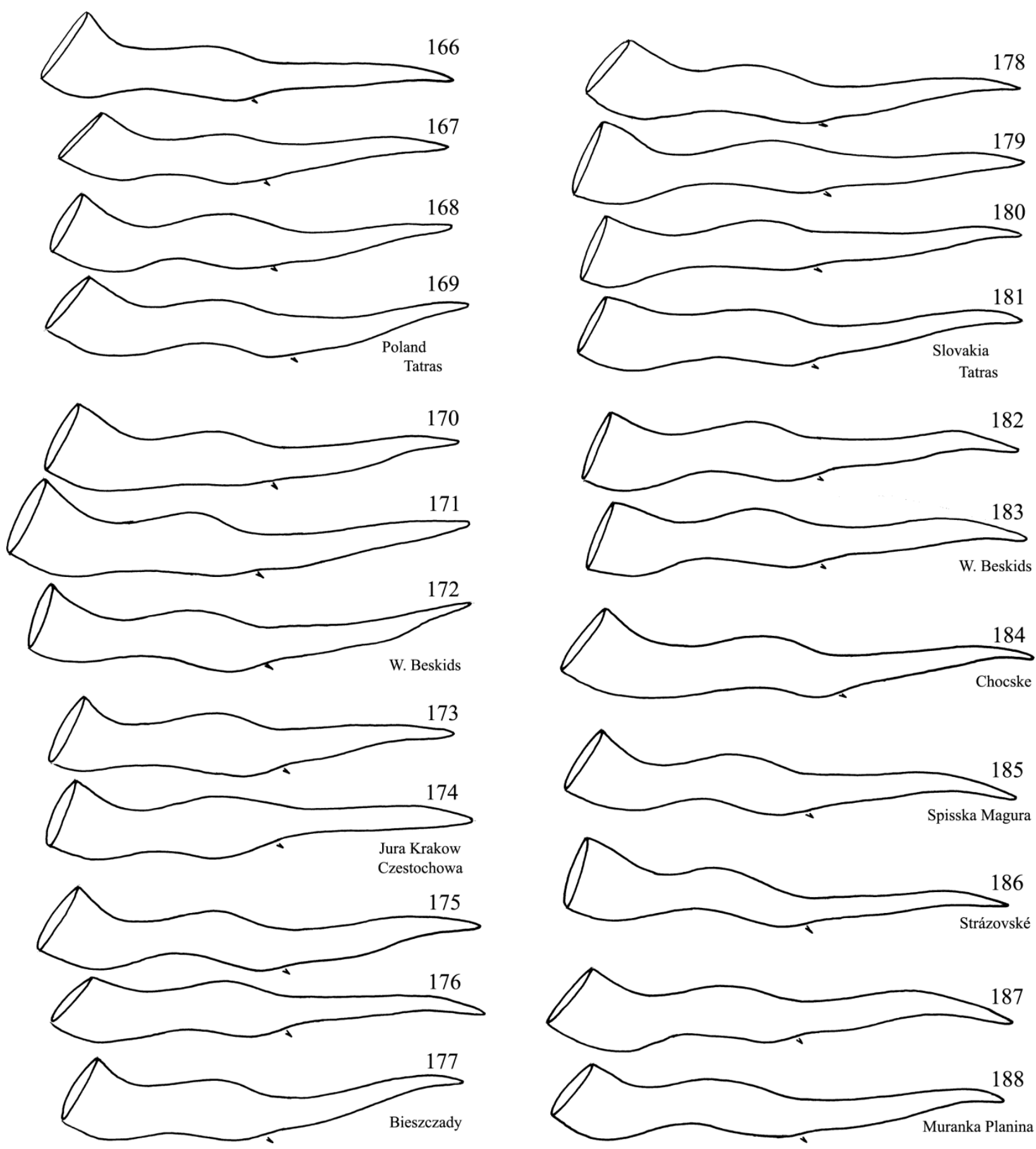

Figures 166-177. Rhyacophila matrensis Oláh \& Szczęsny, sp. nov. Lateral profile of paramere of specimens from Poland. The single spine symbol indicates the position of the group of large spines in order to demonstrate the length of the subterminal paramere shaft.

Figures 178-188. Rhyacophila matrensis Oláh \& Szczęsny, sp. nov. Lateral profile of paramere of specimens from Slovakia. The single spine symbol indicates the position of the group of large spines in order to demonstrate the length of the subterminal paramere shaft. 

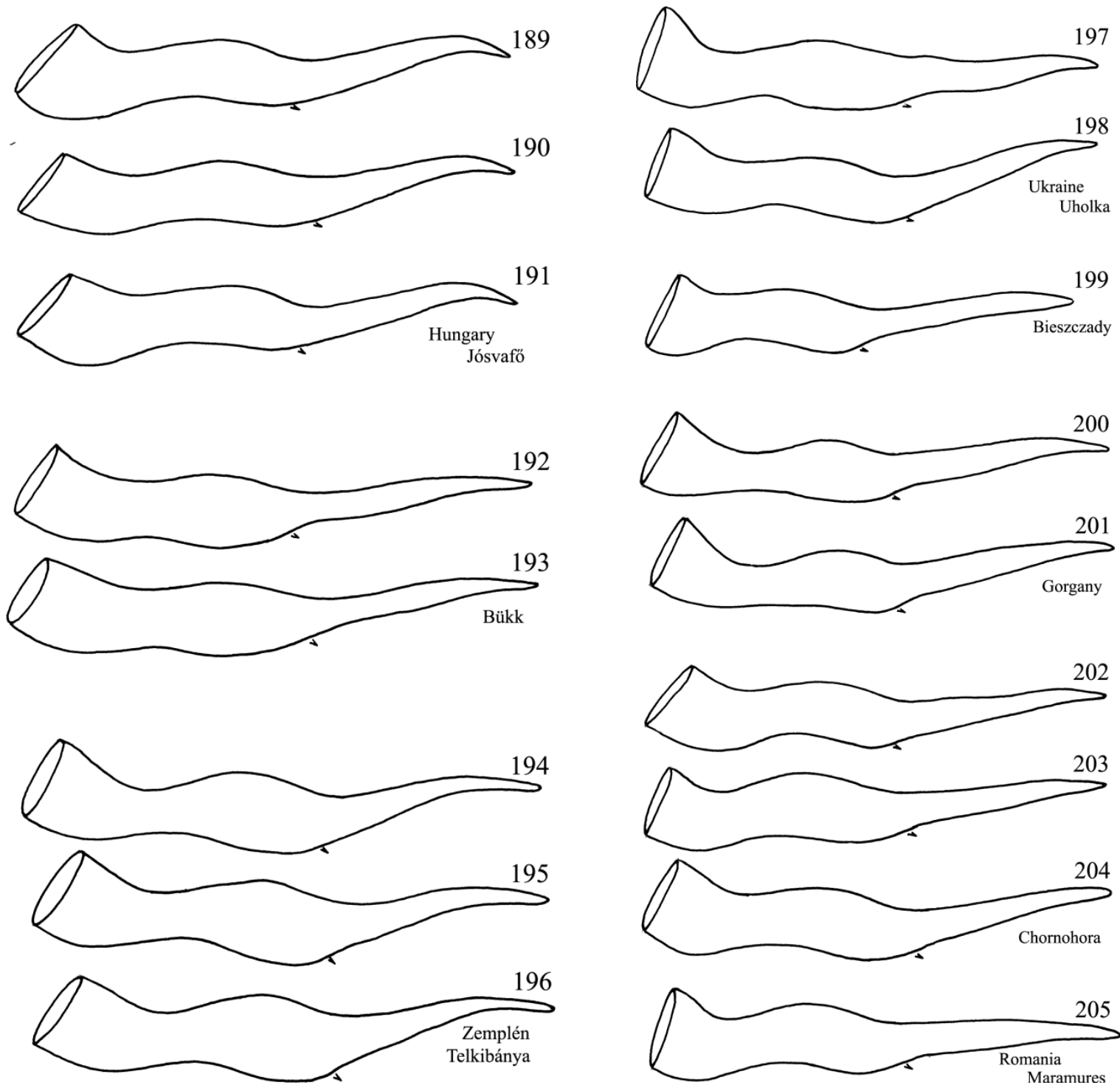

Figures 189-196. Rhyacophila matrensis Oláh \& Szczęsny, sp. nov. Lateral profile of paramere of specimens from Hungary. The single spine symbol indicates the position of the group of large spines in order to demonstrate the length of the subterminal paramere shaft.

Figures 197-205. Rhyacophila matrensis Oláh \& Szczęsny, sp. nov. Lateral profile of paramere of specimens from Ukraine and Romania. The single spine symbol indicates the position of the group of large spines in order to demonstrate the length of the subterminal paramere shaft.

Bâlea Stream along road No.7C, N45³7.154' E2436.754', 1625m, 29.VIII.2012 leg. T. Kovács, D. Murányi, J. Oláh (2 males, OPC).

Description and diagnosis. Head, antennae, maxillary palps, legs and segmental sclerites medium brown. Forewing brown mottled with pale spotted reticulation, very faded in alcohol, forewing length $16 \mathrm{~mm}$. Dorsal shape of the apicodorsal process of segment IX almost regular circular. Lateral shape of the harpago, the second segment of the gonopods obliquely truncate with longer ventrum. The lateral profile of the aedeagus horizontal, rather slim. The ventral shape of 
the ventral process on the aedeagus abbreviated with rounded head. The lateral profile of the left paramere with very elongated middle broadening dilatation; the longitudinal band of the short microtrichia located laterad.

Having large spines and with lateral location of longitudinal band of microtrichia $R$. retezatensis sp. nov. belongs to the Rhyacophila fasciata lineage, as well as having long subterminal paramere shaft it is a member of $R$. matrensis clade of species, most close to $R$. biharensis sp. nov., but differs by having lateral profile of the left paramere with much elongated broad middle region.

Etymology. Named after the mountain region of the type locality.

\section{Rhyacophila rova Oláh \& Coppa, sp. nov.}

(Figures 214-221, 222-223)

Material examined. Holotype: France, Department Pyrénées-Atlantiques, stream along the drainage of Nivelle River, above Saint-Pée-surNivelle, 12-18.VII.1986. light and hand net leg. J.
Oláh \& J. Oláh jun. (1 male, OPC). Allotype: same as holotype (1 female, OPC). Paratypes: same as holotype (27 males, 2 females; OPC). France, Department Pyrénées-Atlantiques, Aste Béon, source d'Aste Béon, 455 m, 25.VIII. 2007, leg. G.Coppa (3 males, OPC). France, Department Hautes-Pyrénées, Borderes-sur-l'Echez, ru la Geline, 306 m, 17.VII.2018, leg. G. Coppa (1 male, OPC).

Description and diagnosis. Head, antennae, maxillary palps, legs and segmental sclerites dark brown. Forewing brown mottled with pale spotted reticulation, very faded in alcohol, forewing length $14 \mathrm{~mm}$. Dorsal shape of the apicodorsal process of segment IX elongated ovoid. Lateral shape of the harpago, the second segment of the gonopods obliquely truncate, slightly concave with longer ventrum. The lateral profile of the aedeagus horizontal, rather slim. The ventral shape of the ventral process on the aedeagus broader basad with narrowing apex. The lateral profile of the left paramere with short ventral hump on the middle expansion; the longitudinal band of the short microtrichia located laterad and restricted to the ventrum, lacking on dorsum.

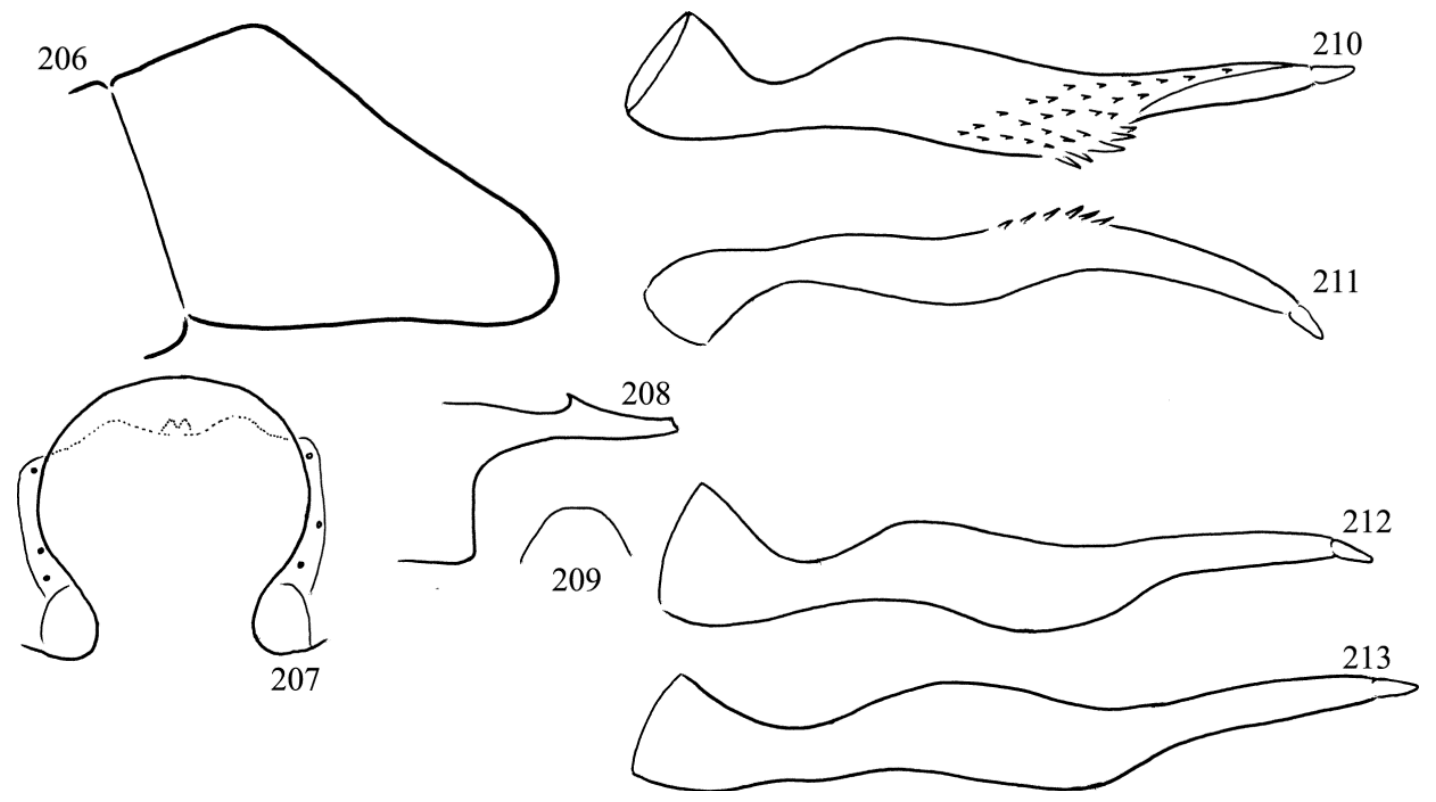

Figures 206-213. Rhyacophila retezatensis Oláh, sp. nov. Holotype male: $206=$ left harpago in left lateral view, $207=$ dorsal process on tergite IX in dorsal view, $208=$ aedeagus in lateral view, $209=$ ventral process of the aedeagus in ventral view, $210=$ left paramere in lateral view, $211=$ left paramere in ventral view. Paratypes: $212-213=$ lateral profile of left paramere. 


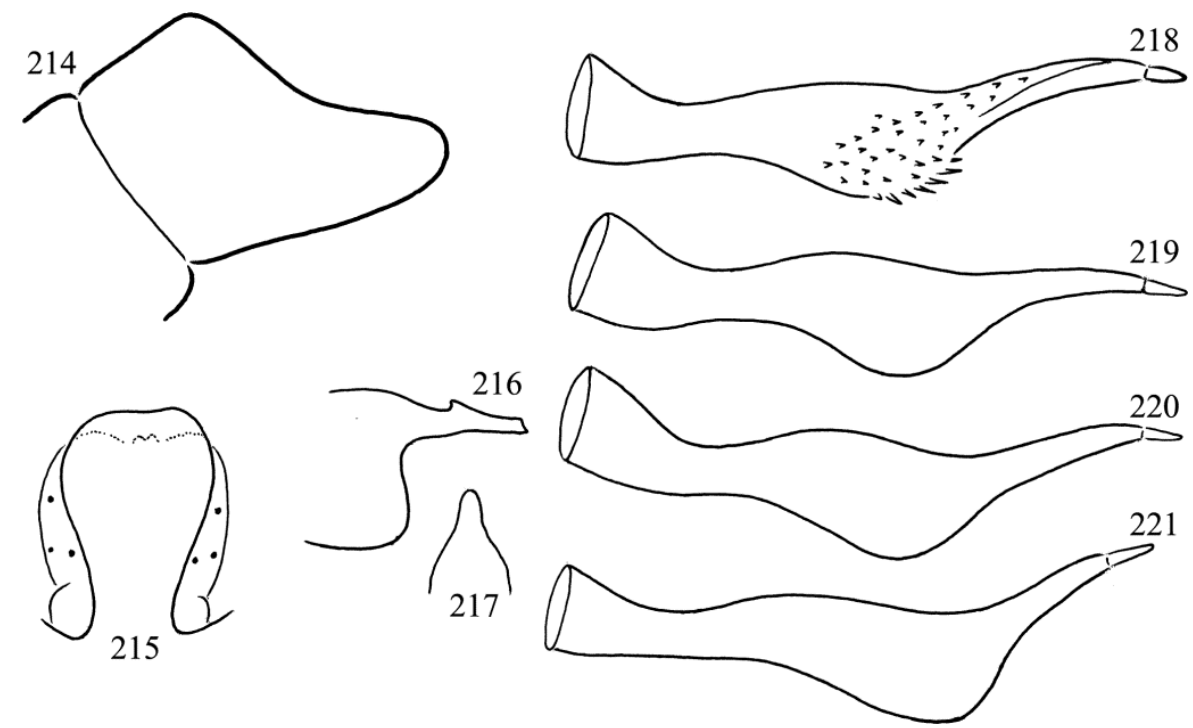

Figures 214-221. Rhyacophila rova Oláh \& Coppa, sp. nov. Holotype male: $214=$ left harpago in left lateral view, $215=$ dorsal process on tergite IX in dorsal view, $216=$ aedeagus in lateral view, $217=$ ventral process of the aedeagus in ventral view, $218=$ left paramere in lateral view. Paratypes: $219=$ lateral profile of left paramere, Nivelle, Pyrénées-Atlantiques, France, $220=$ lateral profile of left paramere, Aste Béon, Pyrénées-Atlantiques, France, 221 = lateral profile of left paramere, Hautes-Pyrénées, France.

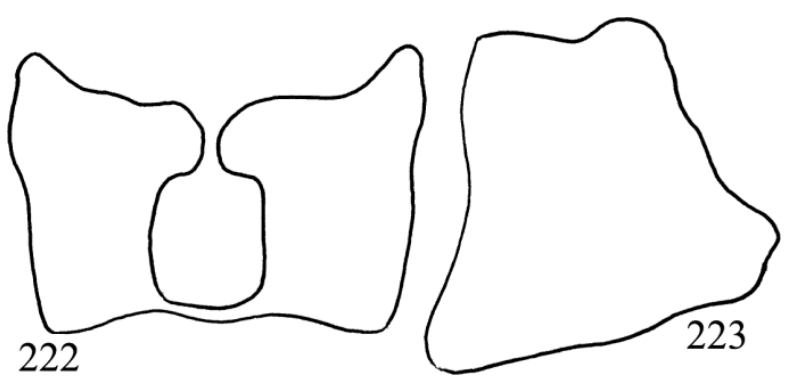

Figures 222-223. Rhyacophila rova Oláh \& Coppa, sp. nov. Allotype female: 222 = sclerites of segment VIII in dorsal view, $223=$ sclerites of segment VIII in lateral view.

Having large spines and with lateral location of longitudinal band of microtrichia $R$. rova sp. nov. belongs to the Rhyacophila fasciata lineage. It is distinguished in the fasciata lineage by the following combination of character states: the ventral extension of the aedeagus has a simple almost vertical lateral profile; several large spines on the paramere ventrum; lateral profile of the paramere with rather flat middle dorsum, without high hump. With this character combination $R$. rova sp. nov. belongs to the $R$. denticulata nested clade and most close to $R$. denticulata, but differs by having the sub-basal region short and thick, not long and slender; microtrichial band on the paramere less broad anterad; the ventrum of the middle expanded region with shorter hump; The female of $R$. rova has the sclerite of segment VIII with monolobed ventral region in lateral view.

Etymology. rova, euphemic coining form "rövid-vastag" short and thick in Hungarian, refers to the shape of the sub-basal region of the paramere, that is short and thick compared to its sibling Rhyacophila denticulata.

\section{Rhyacophila ruda Oláh \& Johanson, sp. nov.}

(Figures 224-232, 233-234)

Material examined. Holotype: Sweden, Skåne, Axeltorps skogar Nature Reserve, $56.4046^{\circ} \mathrm{N}$, $12.8396^{\circ} \mathrm{E}$, light trap, 24.V.2016, leg. K.A. Johanson (1 male, SMNH). Allotype: same as holotype (1 female, SMNH).

Description and diagnosis. Head, antennae, maxillary palps, legs and segmental sclerites dark brown. Forewing brown mottled with pale spotted reticulation, very faded in alcohol, forewing 


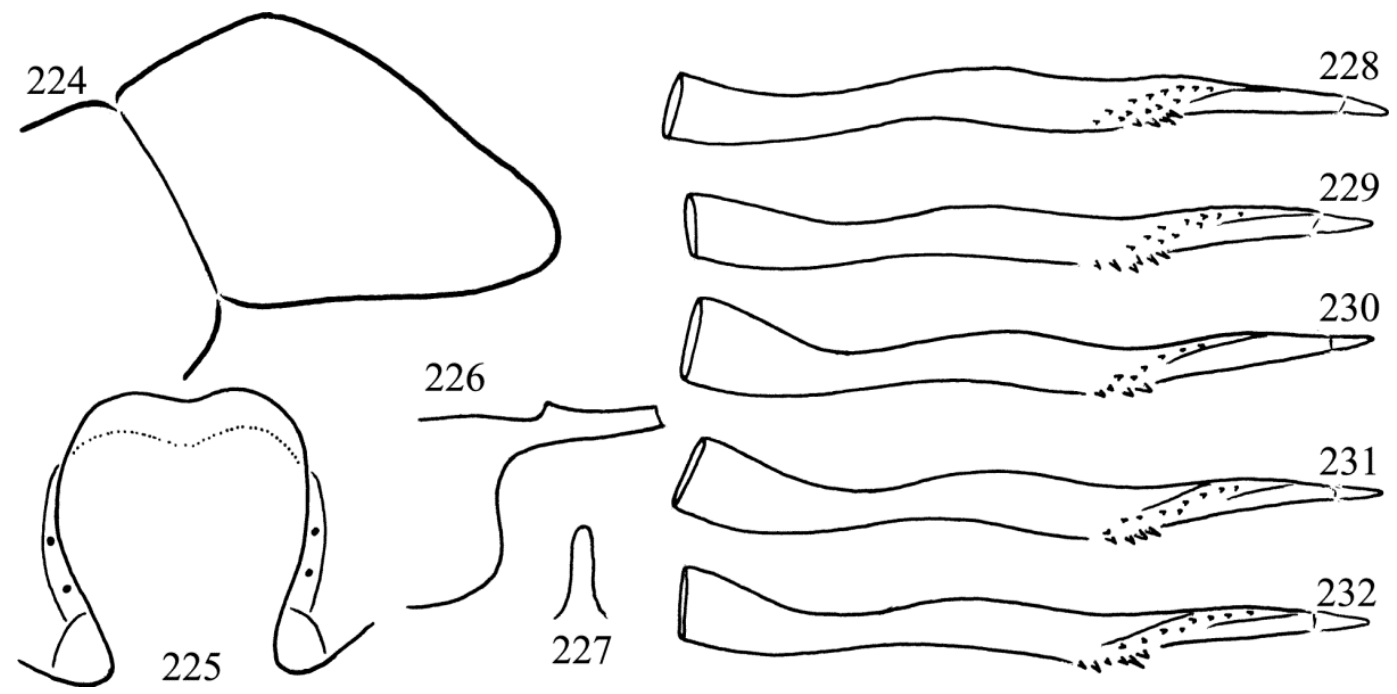

Figures 224-232. Rhyacophila ruda Oláh \& Johanson, sp. nov. Holotype male: $224=$ left harpago in left lateral view, $225=$ dorsal process on tergite IX in dorsal view, $226=$ aedeagus in lateral view, $227=$ ventral process of the aedeagus in ventral view, 228 = left paramere in lateral view, 229-232 = lateral profile of left paramere redrawn or drawn with slight viewing angle modification.

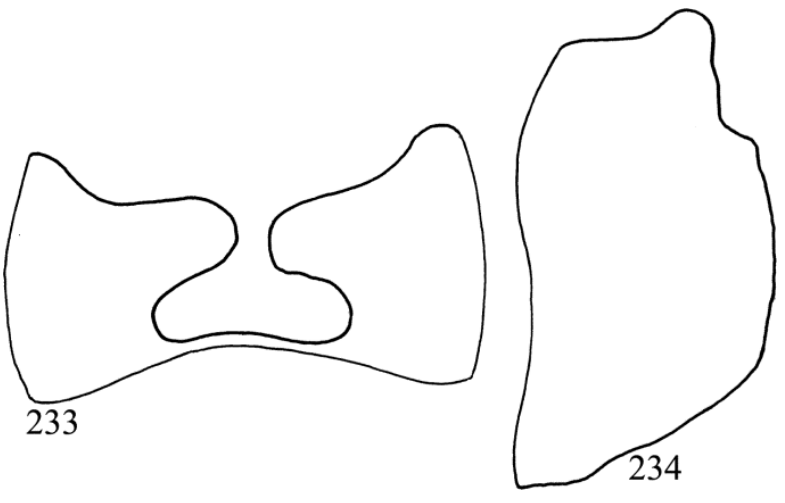

Figures 233-234. Rhyacophila ruda Oláh \& Johanson, sp. nov. Allotype female: 233 = sclerites of segment VIII in dorsal view, 234 = sclerites of segment VIII in lateral view.

length $13 \mathrm{~mm}$. Dorsal shape of the apicodorsal process of segment IX elongated ovoid. Lateral shape of the harpago, the second segment of the gonopods obliquely truncate with longer ventrum. The lateral profile of the aedeagus horizontal, rather slim. The ventral shape of the ventral process on the aedeagus long digitate. The lateral profile of the left paramere almost regular rod shaped without sound dilatation of middle broadening.
Having large spines and with lateral location of longitudinal band of microtrichia Rhyacophila. ruda sp. nov, belongs to the $R$. fasciata lineage, as well as having short subterminal paramere shaft it is a member of $R$. fasciata clade of species. The general pattern of the paramere is most close to that of $R$. fasciata but differs by having almost rod-shaped lateral profile, the well differentiated basal, subbasal, middel and subterminal regions are disappeared, just discernible.

Etymology. ruda, coined form "rúd" rod in Hungarian, refers to the simple rod-shaped paramere produced by disappearing its distinct regions.

\section{Rhyacophila salfa Oláh, sp. nov.}

(Figures 235-245)

Material examined. Holotype: Bosnia \& Herzegovina, Neretva River, $4 \mathrm{~km}$ above $\mathrm{N}$ of Mostar, 13.IX.1988, singled leg. J. Oláh (1 male, OPC). Paratypes: same as holotype (16 males, OPC). 


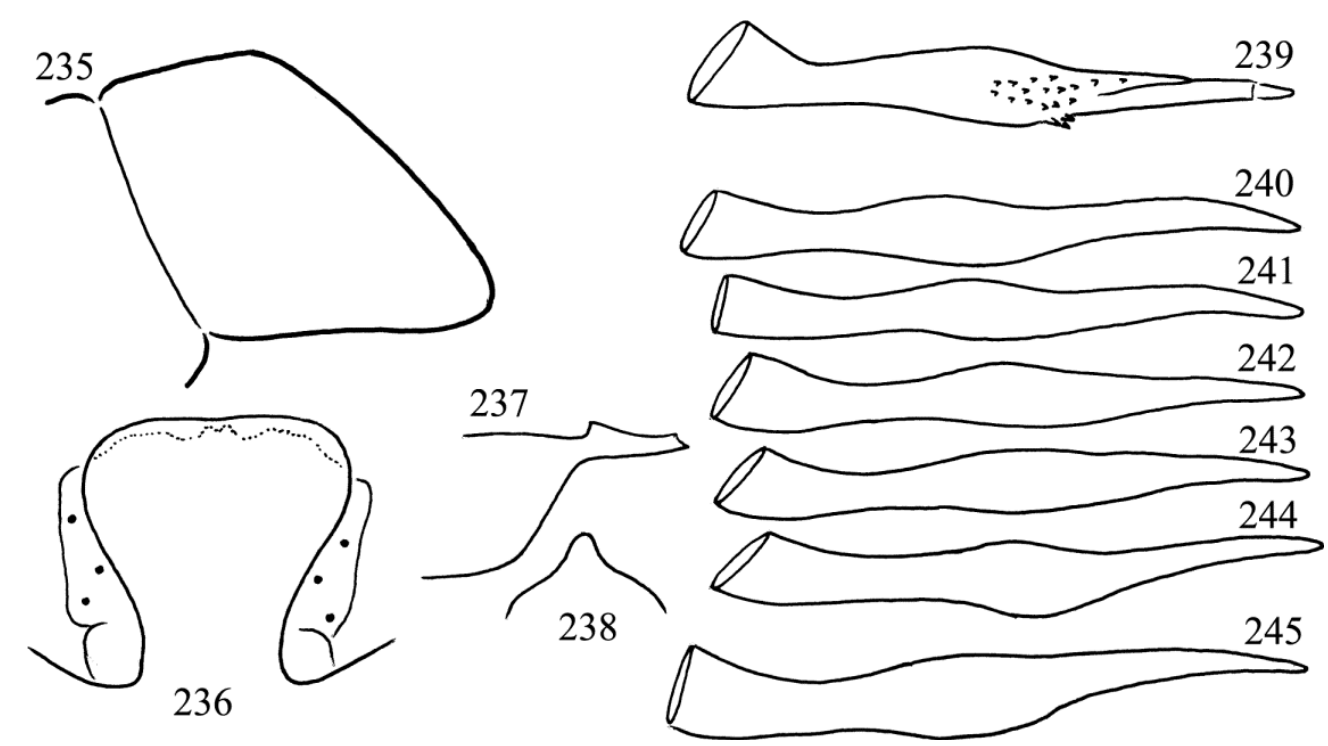

Figures 235-245. Rhyacophila salfa Oláh, sp. nov. Holotype male: $235=$ left harpago in left lateral view, $236=$ dorsal process on tergite IX in dorsal view, $237=$ aedeagus in lateral view, $238=$ ventral process of the aedeagus in ventral view, 239 = left paramere in lateral view. Paratypes: $240-245$ = lateral profile of left paramere.

Description and diagnosis. Head, antennae, maxillary palps, legs and segmental sclerites dark brown. Forewing brown mottled with pale spotted reticulation, very faded in alcohol, forewing length $13 \mathrm{~mm}$. Dorsal shape of the apicodorsal process of segment IX fun-shaped with narrow neck. Lateral shape of the harpago, the second segment of the gonopods obliquely truncate with longer ventrum. The lateral profile of the aedeagus horizontal, rather slim. The ventral shape of the ventral process on the aedeagus very broad based with small digitate central lobe. The lateral profile of the left paramere almost regular rod shaped with small dilatation of middle broadening.

Having large spines and with lateral location of longitudinal band of microtrichia Rhyacophila salfa sp. nov. belongs to the $R$. fasciata lineage, as well as having short subterminal paramere shaft it is a member of $R$. fasciata clade of species. The general pattern of the paramere is most close to $R$. ruda sp. nov. but, differs by having shorter paramere that is similarly straight but the distinctly differentiated basal, subbasal, middel and subterminal regions are well discernible. Moreover the shape of the neutral characters of the dorsal process of segment IX and the ventral lobe of the aedeagus are different.

Etymology. salfa, coined form "szálfa" log or straight-tree in Hungarian, refers to the simple straight-shaped paramere with reduced distinct regions.

\section{Rhyacophila sociata Navas, 1919}

(Figures 246-252)

Rhyacophila sociata Navas, 1916:10-11: „Similis fasciatae Hag.” „valvis copulatoris arcuatis, acutis, inferne ad partem dilatatam denticulatis.” „Patria. Solares (Santander), 10 de Julio de 1915. Un solo ejeplar cogi en una bella y breve excursión realizada deste Santander en campaňia de Luis Alaejos y D. Enrique Millán.”

Rhyacophila denticulata McLachlan, 1879: Schmid, F. 1970: 120 synonymized with.

Rhyacophila sociata: Valladolid et al. 2018: 530. After a systematic search at University of Zaragoza and at Museo de Ciencias Naturales of Barcelona it was concluded that the single type specimen has been lost. A neotype was designated with type locality: Spain, La Rioja Province, River Oja and the species status was resurrected. 


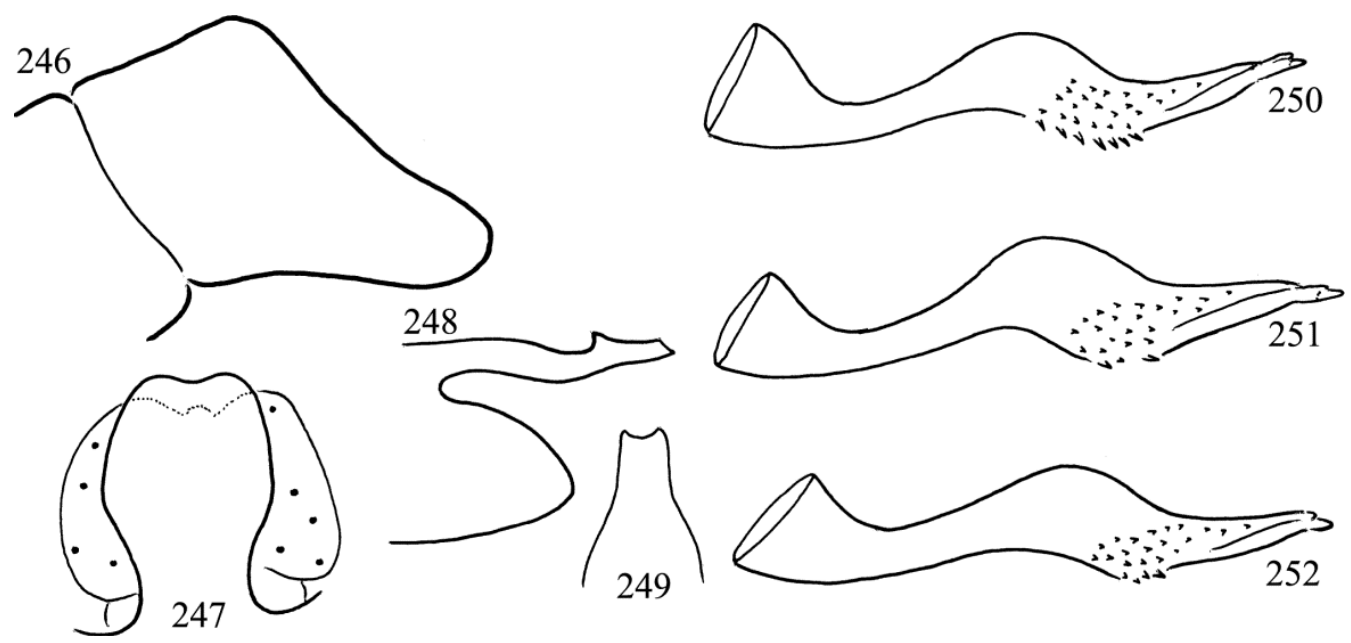

Figures 246-252. Rhyacophila sociata Navas, 1919 Male: $246=$ left harpago in left lateral view, $247=$ dorsal process on tergite IX in dorsal view, $248=$ aedeagus in lateral view, $249=$ ventral process of the aedeagus in ventral view, $250=$ left paramere in lateral view, Cantabria, Cillorigo de Liébana, Spain, 251 = left paramere in lateral view, Cantabria, Cieza, Spain, 252 = lateral profile of left paramere, Cantabria, Vega de Liebana, Spain.

Material examined. Spain, Cantabria, Cillorigo de Liébana, la Deva, defila Hermida, $200 \mathrm{~m}$, 10.VII.2016, leg. G. Coppa (1 male, OPC). Spain, Cantabria, Cieza , arroyo del Candanoso, puente tricha, 280m, 7.XI.2012, leg. G. Coppa (1 male, OPC). Spain, Cantabria, Vega de Liebana, rio Frio el Molino, $580 \mathrm{~m}$, 10.VII.2016, leg. G. Coppa (1 male, OPC).

Re-diagnosis. Rhyacophila sociata Navas was described from Cantabria, Spain. We have examined three male specimens from three localities in Cantabria and recorded similar paramere organisation. In the $R$. sociata nested clade it is most close to $R$. soreda sp. nov. but distinguished by the following combination of character states: the triangular lateral profile of the ventral extension of the aedeagus has a blunt apex, not pointed; the lateral profile of the paramere with shorter middle extension; the subterminal paramere shaft is longer and robust, not short and slender; the bifid terminal apex is unique, every species in the Rhyacophila fasciata species complex has simple undivided apex. This bifid apex is constituted by the small dark pigmented terminal seta and by the over-running ending of the horizontal ridge of the subterminal shaft. The neutral, non-adaptive character of the ventral lobe on the aedeagus has excised apex.

\section{Rhyacophila soreda Coppa \& Oláh, sp. nov.}

(Figures 253-260, 261-262)

Material examined. Holotype: France, Department Pyrénées-Orientales, Sorède, la Massane, 195 m, 28.V.2009, leg. G. Coppa (1 male, CPC). Allotype: same as holotype (1 female).

Description and diagnosis. Head, antennae, maxillary palps, legs and segmental sclerites dark brown. Forewing brown mottled with pale spotted reticulation, very faded in alcohol, forewing length $12 \mathrm{~mm}$. Dorsal shape of the apicodorsal process of segment IX elongated subquadrangular with constricted basal neck. Lateral shape of the harpago, the second segment of the gonopods obliquely truncate, slightly concave with longer ventrum. The lateral profile of the aedeagus horizontal, rather slim and short. The triangular ventral extension of the aedeagus is pointed. The ventral shape of the ventral process on the aedeagus digitate with broadening basal third. The lateral profile of the left paramere with elongated and oblique middle extension; the longitudinal band of the short microtrichia located laterad and distributed on the posterior half of the extended middle region. The subterminal paramere shaft short broad with narrowing apex. 


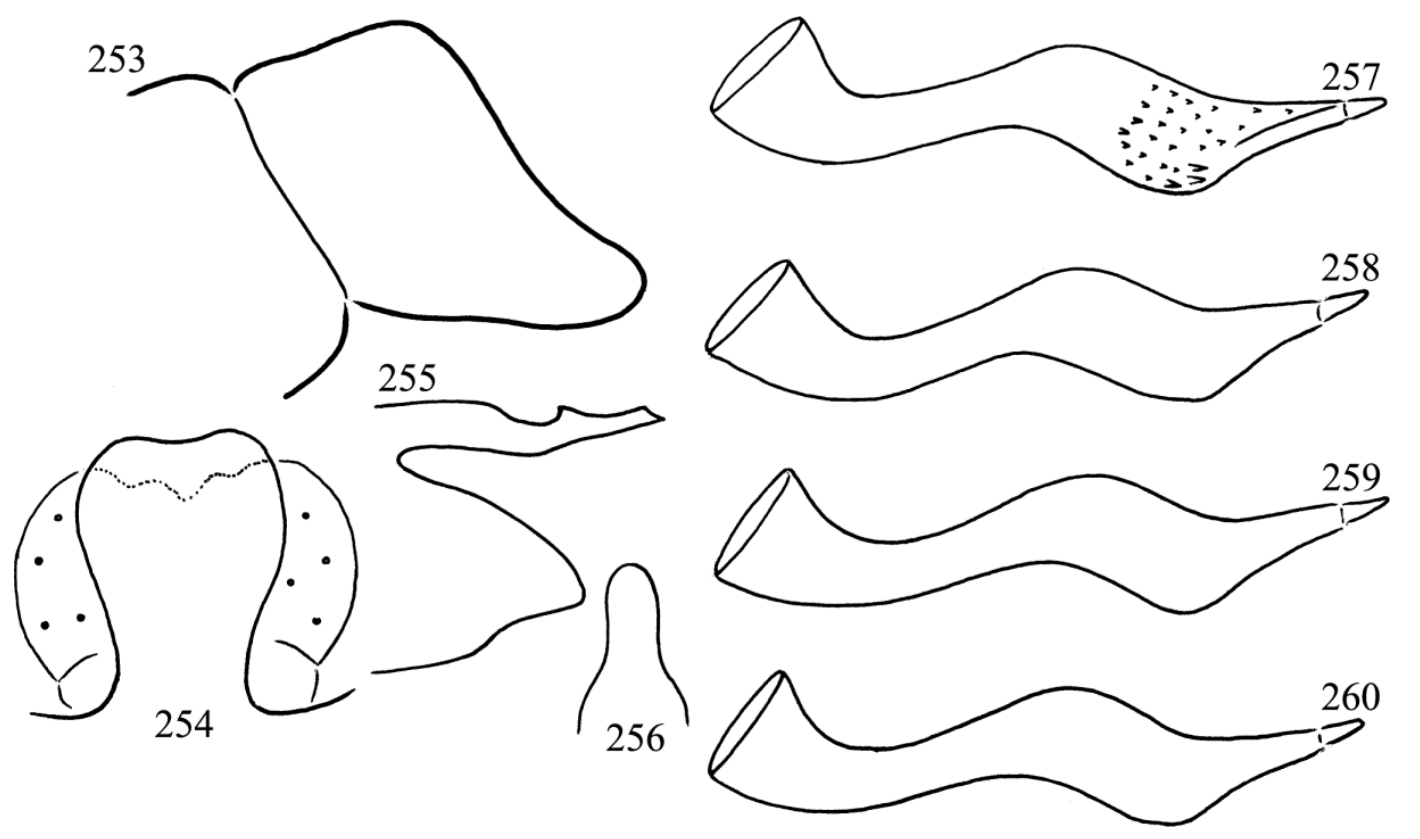

Figures 253-260. Rhyacophila soreda Coppa \& Oláh, sp. nov. Holotype male: $253=$ left harpago in left lateral view, $254=$ dorsal process on tergite IX in dorsal view, $255=$ aedeagus in lateral view, $256=$ ventral process of the aedeagus in ventral view, 257 = left paramere in lateral view, 258-260 = lateral profile of left paramere redrawn or drawn with slight viewing angle modification.
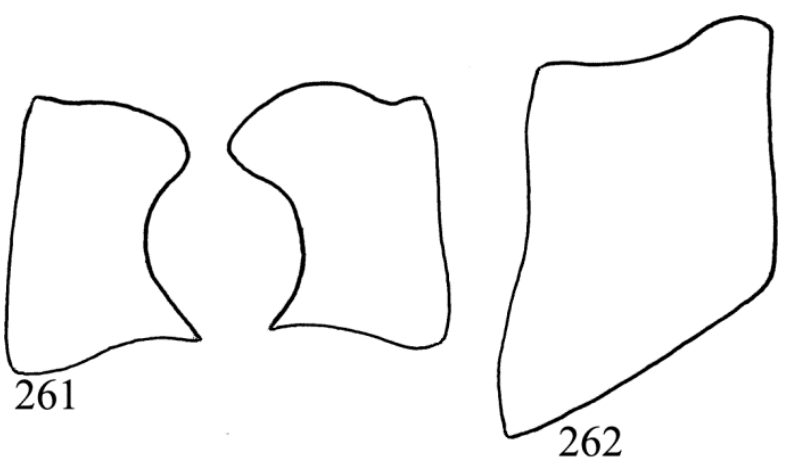

Figures 261-262. Rhyacophila soreda Coppa \& Oláh, sp. nov. Allotype female: 261 = sclerites of segment VIII in dorsal view, $262=$ sclerites of segment VIII in lateral view.

Having large spines and with lateral location of longitudinal band of microtrichia $R$. soreda $\mathrm{sp}$. nov. belongs to the Rhyacophila fasciata lineage. It is a member of $R$. sociata nested clade distinguishable by the following combination of character states: the ventral extension of the aedeagus has a triangular lateral profile; lateral profile of the paramere with a high hump on middle dorsum. $R$. soreda sp. nov. is distinguished from $R$. sociata Navas by the following combination of character states: the triangular lateral profile of the ventral extension of the aedeagus has a pointed apex, not blunt; the lateral profile of the paramere with longer middle extension; the subterminal paramere shaft is shorter and slender, not long and robust; the terminal paramere apex is simple not bifid. The female sclerite complex on segment VIII differs from that of $R$. coppai sp. nov. In dorsal view the apicomesal lobe is broad rounded, not narrowing. We have no female of $R$. sociata to compare.

Etymology. Named after the type locality.

\section{Rhyacophila suna Oláh, sp. nov.}

(Figurers 263-270)

Material examined. Holotype: Turkey, NW Anatolia, Bolu prov., streamlet - inlet of Abant Gölü (1400 m), 13.6.1998, P. Chvojka leg. (1 m, NMPC).

Description and diagnosis. Head, antennae, maxillary palps, legs and segmental sclerites dark 


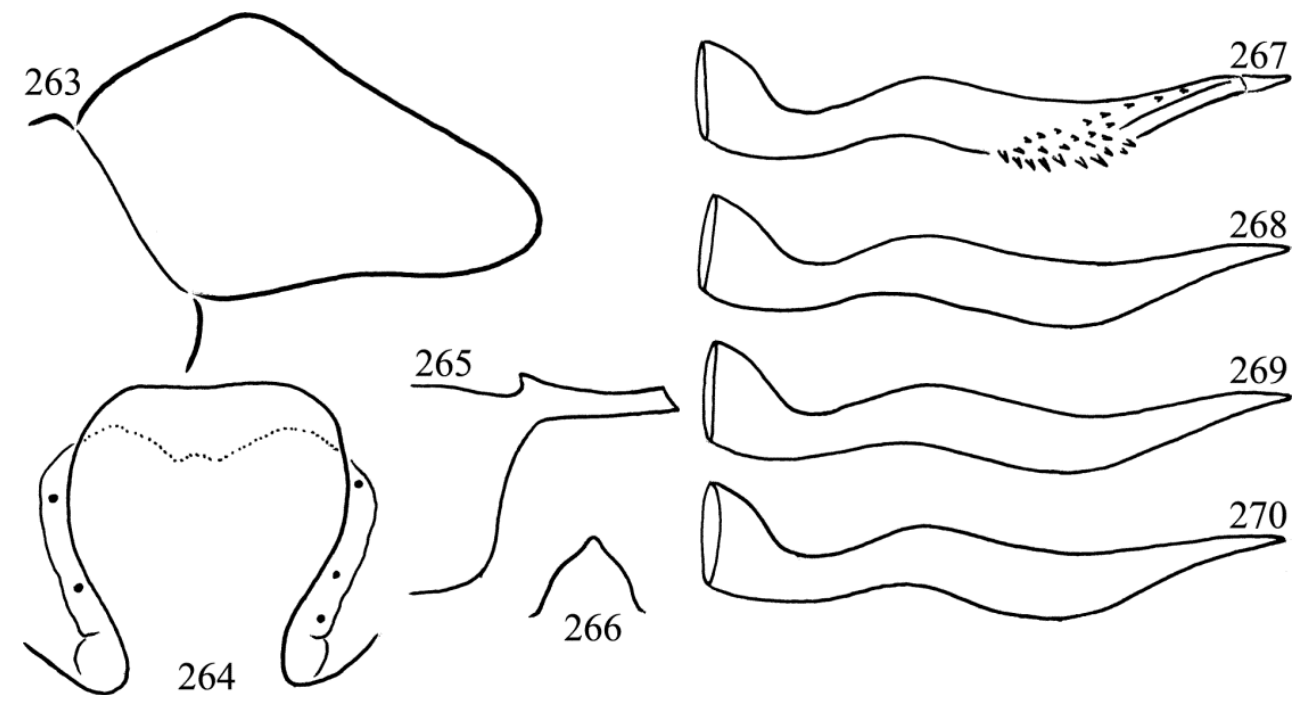

Figures 263-270. Rhyacophila suna Oláh, sp. nov. Holotype male: $263=$ left harpago in left lateral view, $264=$ dorsal process on tergite IX in dorsal view, 265 = aedeagus in lateral view, $266=$ ventral process of the aedeagus in ventral view, $267=$ left paramere in lateral view, 268-270 = lateral profile of left paramere redrawn or drawn with slight viewing angle modification.

brown. Forewing brown mottled with pale spotted reticulation, very faded in alcohol, forewing length $14 \mathrm{~mm}$. Dorsal shape of the apicodorsal process of segment IX slightly rounded with moderately narrow neck. Lateral shape of the harpago, the second segment of the gonopods obliquely truncate with longer ventrum. The lateral profile of aedeagus horizontal, rather slim. The ventral shape of the ventral process on the aedeagus broad with pointed small apical triangular outgrowth. The lateral profile of the paramere slim, S-shaped with enlarged ventral spiny area.

Having large spines and with lateral location of longitudinal band of microtrichia Rhyacophila. suna sp. nov, belongs to the $R$. fasciata lineage, as well as having short subterminal paramere shaft it is a member of $R$. fasciata clade of species. The general pattern of the paramere is most close to $R$. fasciata Hagen, but differs by having more slender, S-shaped lateral profile and a large ventral spiny area.

Etymology. suna, coined form "sün" hedgehog in Hungarian, refers to the enlarged spiny ventral region on the paramere.
Rhyacophila tuhega Oláh, sp. nov.

(Figures 271-279)

Material examined. Holotype: Albania, Gjirokastër county, Finiq municipality, Syri i Kaltër spring, N39 55'23", E020 11'30", 155 m, 03.XI. 2018, leg. S. Beshkov \& A. Nahirnic (1 male, OPC). Paratypes: same as holotype (4 males, $\mathrm{OPC}$ ).

Description and diagnosis. Head, antennae, maxillary palps, legs and segmental sclerites dark brown. Forewing brown mottled with pale spotted reticulation, very faded in alcohol, forewing length $12 \mathrm{~mm}$. Dorsal shape of the apicodorsal process of segment IX rounded slightly elongated with moderately narrow neck. Lateral shape of the harpago, the second segment of the gonopods obliquely truncate with longer ventrum. The lateral profile of the aedeagus horizontal, rather slim. The ventral shape of the ventral process on the aedeagus small rounded triangular. The lateral profile of the paramere slim with sharply pointed terminal ending; microtrichian band located mesad and middle dorsad. 

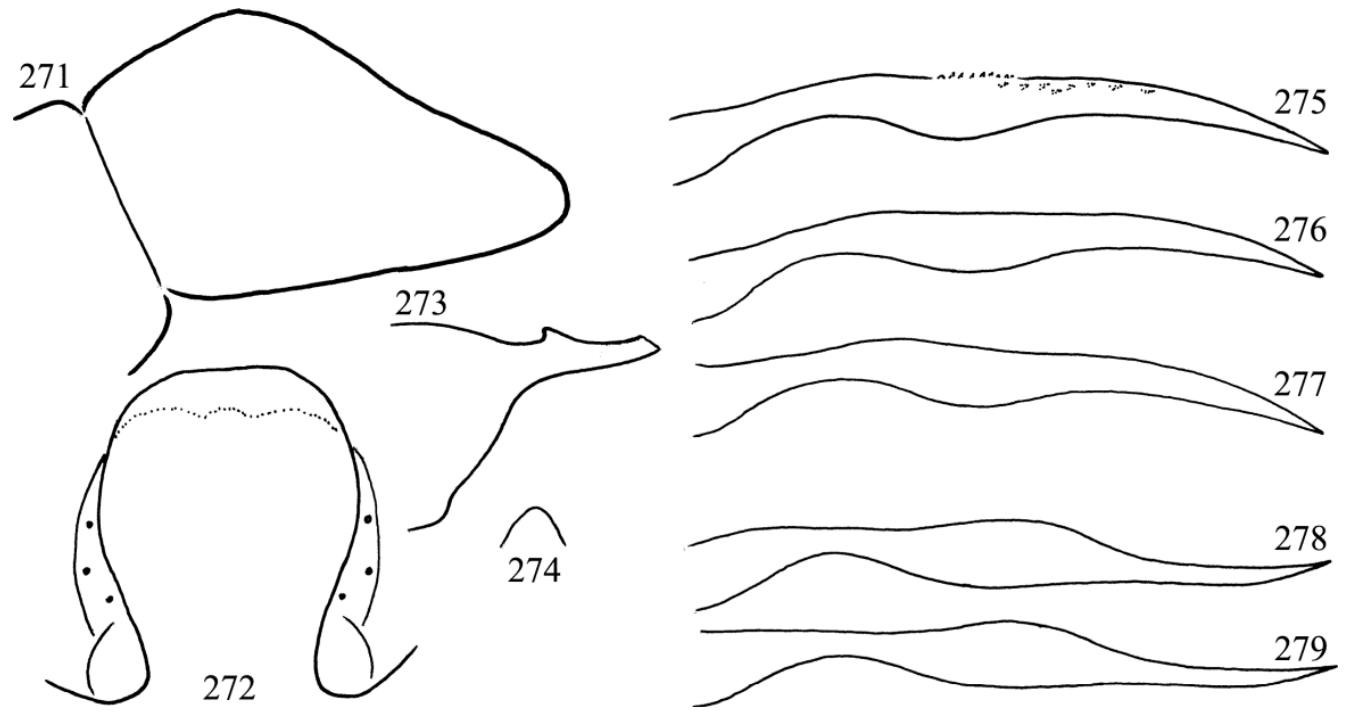

Figures 271-279. Rhyacophila tuhega Oláh, sp. nov. Holotype male: $271=$ left harpago in left lateral view, $272=$ dorsal process on tergite IX in dorsal view, $273=$ aedeagus in lateral view, $274=$ ventral process of the aedeagus in ventral view, $275=$ left paramere in lateral view. Paratypes: $276-277=$ lateral profile of left paramere, $278-279=$ ventral profile of left paramere.

Having slender parameres without large spines and with mesal location of longitudinal band of microtrichia Rhyacophila tuhega sp. nov, belongs to the $R$. mysica lineage. The general pattern of the paramere and the neutral characters of dorsal process of segment IX and the harpago relate this new species to $R$. isparta Sipahiler but, differs by the shape of harpago, dorsal process of segment IX, cerci as well as the ventral shape of the paramere.

Etymology. tuhega, coined form "tü hegy" needle point in Hungarian, refers to the very thin pointed paramere terminal.

\section{Rhyacophila zemplenensis Oláh, sp. nov.}

(Figures 280-288)

Material examined. Holotype: Hungary, Zemplén Mts. Kemence valley, spring stream to the Kemence stream, near Kökapu, 48.427035N, 21.440819E, 9.VIII.1966 hand net leg. J. Oláh (1 male, OPC). Paratypes: same as holotype (3 males, OPC). Slovakia, E Slovakia, Bukovské vrchy Hills, Stužická rieka brook $(660 \mathrm{~m})$, 18.VII.1990, leg. P. Chvojka (1 male, OPC; 1 male, NMPC).
Description and diagnosis. Head, antennae, maxillary palps, legs and segmental sclerites dark brown. Forewing brown mottled with pale spotted reticulation, very faded in alcohol, forewing length $14 \mathrm{~mm}$. Dorsal shape of the apicodorsal process of segment IX almost regular circular with narrow neck. Lateral shape of the harpago, the second segment of the gonopods obliquely truncate with longer ventrum. The lateral profile of the aedeagus horizontal, rather slim. The ventral shape of the ventral process on the aedeagus abbreviated with narrowing head. The lateral profile of the left paramere characterized by broad basal half formed by the fused basal, subbasal and middle regions; the longitudinal band of the short microtrichia located laterad.

Having large spines and with lateral location of longitudinal band of microtrichia $R$. zemplenensis sp. nov. belongs to the Rhyacophila fasciata lineage, as well as having long subterminal paramere shaft it is a member of $R$. matrensis clade of species but differs by all having lateral profile of the left paramere with fused broad basal half.

Etymology. Named after the type locality (Zemplén Mts.). 


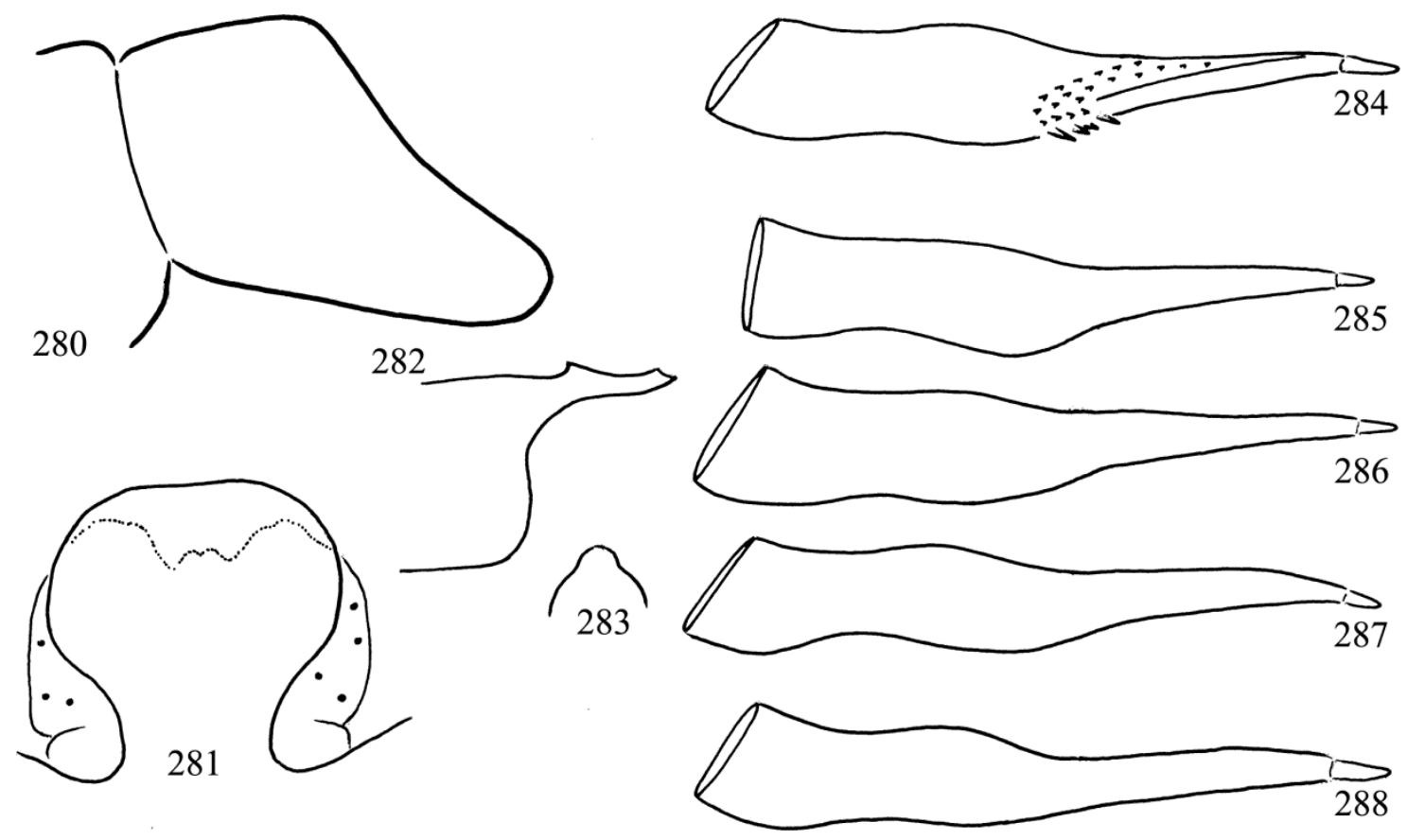

Figures 280-288. Rhyacophila zemplenensis Oláh, sp. nov. Holotype male: $280=$ left harpago in left lateral view, $281=$ dorsal process on tergite IX in dorsal view, 282 = aedeagus in lateral view, $283=$ ventral process of the aedeagus in ventral view, 284 = left paramere in lateral view. Paratypes: $285-287=$ lateral profile of left paramere, Hungary,

$288=$ ventral profile of left paramere, Slovakia.

Remarks. The holotype and the three paratypes from the type locality have been collected by sweep netting along a short spring stream, a small side spring in the Kemence valley of the Kemence stream in the Zemplén Mts. The ancestral species of the lineage $R$. matrensis populates the stream habitats in the same mountains.

Acknowledgement - We acknowledge the sample contribution of our colleagues: Pavel Chvojka, Department of Entomology National Museum, Praha, Czech Republic; JeanLuc Gattoliatt, Musée cantonal de zoologie, Lausanne, Switzerland; Wolfram Graf, Institute of Hydrobiology and Aquatic Ecology Management, University of Natural Resources and Applied Life Sciences, Vienna, Austria; Halil Ibrahimi, University of Prishtina, Faculty of Mathematics and Natural Sciences, Department of Biology, Prishtina, Kosovo; Peter Neu, Heiligenbungert, Kasel, Germany.

\section{REFERENCES}

Hagen, H. (1859): Die Phryganiden Pictet's. Entomologische Zeitung, 20(4-6): 131-170.

MALICKY, H. \& F. SIPAHILER (1993): Köscherfliegen (Trichoptera) aus der Türkei, mit Bemerkungen zu weiteren mediterranen Köcherfliegen. Bulletin de la Société entomologique Suisse, 66: 457-478.

MCLACHLAN, R. (1874-1880): A monographic revision and synopsis of the Trichoptera of the European fauna. Reprinted 1968. E.W.Classey Ltd. Hampton, Middlesex, 523 pp. +59 plts. doi: 10.5962/bhl.title.28556

NAVAS, L. (1916): Tricópteros nuevos de Espaňa. Broteria, la Serie, Serie Zoológica, 14: 5-11.

NAVAS, L. (1923): Excursions entomologiques de l'Istiu de 1922. Arxius de l'Institut de Ciènces, 8: 1-34

OlÁH, J. ANDERSEn, T., BeshKov, S., Coppa G., Ruiz GARCIA, A. \& JOHANSON K.A. (2019): Revision of European Wormaldia species (Trichoptera, Philopotamidae): Incongruent chimeric taxa of integrative organization. Opuscula Zoologica, Budapest, 50(1): 31-85. doi: 10.18348/opzool.2019.1.31

Oláh, J., Vinçon, G., ChVoJKa, P., Kovács, T. \& MANKO, P. (2020): On the Trichoptera of the Caucasus. (In prep.)

SCHMID, F. (1970): Le genre Rhyacophila et la famille des Rhyacophilidae (Trichoptera). Mémoires de la Société Entomologique du Canada, 66: 1-230. doi: $\underline{10.4039 / \mathrm{entm} 10266 \mathrm{fv}}$ 
SIPAHILER, F. (1996): Studies on the Trichoptera fauna of southern Anatolia. Entomofauna, Zeitschrift für Entomologie, 17(16): 293-312.

SIPAHILER, F. (2006): New species of Trichoptera from Turkey and the description of the unknown female of Drusus ingridae Sipahiler, 1993 (Rhyacophilidae, Polycentropodidae, Hydropsychidae, Limnephilidae). Braueria (Lunz am See, Austria), 33: 2022 .

SIPAHILER, F. (2018): A new subspecies of Rhyacophila fasciata Hagen from northern Turkey with a description of the unknown female of Rhyacophila fasciata mysica Malicky \& Sipahiler (Trichoptera, Rhyacophilidae). Braueria (Lunz am See, Austria), 45: $15-18$.
Valladolid, M., Arauzo, M., Dorda, B.A. \& ReY, I. (2018): The Rhyacophila fasciata Group in Western Europe: Confirmation of Rhyacophila denticulata McLachlan 1879 (stat. prom.) and Rhyacophila sociata Navás 1916 (stat. res.), based on morphological and molecular genetic evidence (Trichoptera: Rhyacophilidae). Zootaxa, 4418(6): 526-544. doi: 10.11646/zootaxa.4418.6.2

Valladolid, M., Karaouzas, I., Arauzo, M., DorDA, BA. \& REY, I. (2019): The Rhyacophila fasciata Group in Greece: Rhyacophila kykladica Malicky \& Sipahiler 1993 (stat. prom.) (Trichoptera: Rhyacophilidae). Morphological description, genetic and ecological features. Zootaxa, 4657(3): 503-522. doi: 10.11646/zootaxa.4657.3.5 